\title{
Effect of horizontal resolution on the simulation of tropical cyclones in the Chinese Academy of Sciences FGOALS-f3 climate system model
}

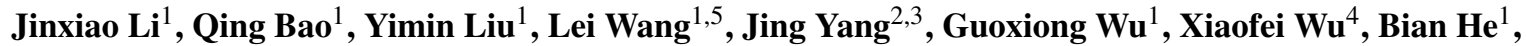 \\ Xiaocong Wang ${ }^{1}$, Xiaoqi Zhang ${ }^{6,1}$, Yaoxian Yang ${ }^{1}$, and Zili Shen ${ }^{7,1}$ \\ ${ }^{1}$ State Key Laboratory of Numerical Modeling for Atmospheric Sciences and Geophysical Fluid Dynamics, \\ Institute of Atmospheric Physics, Chinese Academy of Sciences, Beijing 100029, China \\ ${ }^{2}$ State Key Laboratory of Earth Surface Processes and Resource Ecology, Faculty of Geographical Science, \\ Beijing Normal University, Beijing 100875, China \\ ${ }^{3}$ Southern Marine Science and Engineering Guangdong Laboratory, Guangzhou 511458, China \\ ${ }^{4}$ School of Atmospheric Sciences/Plateau Atmosphere and Environment Key Laboratory of Sichuan Province, \\ Chengdu University of Information Technology, Chengdu 610225, China \\ ${ }^{5}$ College of Earth and Planetary Sciences, University of Chinese Academy of Sciences, Beijing 100049, China \\ ${ }^{6}$ School of Atmospheric Sciences, Nanjing University of Information Science and Technology, Nanjing 210044, China \\ ${ }^{7}$ Collaborative Innovation Center on Forecast and Evaluation of Meteorological Disasters, \\ Nanjing University of Information Science and Technology, Nanjing 210044, China
}

Correspondence: Qing Bao (baoqing@mail.iap.ac.cn)

Received: 30 January 2021 - Discussion started: 15 March 2021

Revised: 7 September 2021 - Accepted: 13 September 2021 - Published: 12 October 2021

\begin{abstract}
The effects of horizontal resolution on the simulation of tropical cyclones were studied using the Chinese Academy of Sciences Flexible Global Ocean-AtmosphereLand System Finite-Volume version 3 (FGOALS-f3) climate system model from the High-Resolution Model Intercomparison Project (HighResMIP) for the Coupled Model Intercomparison Project phase 6 (CMIP6). Both the lowresolution (about $100 \mathrm{~km}$ resolution) FGOALS-f3 model (FGOALS-f3-L) and the high-resolution (about $25 \mathrm{~km}$ resolution) FGOALS-f3 (FGOALS-f3-H) models were used to achieve the standard Tier 1 experiment required by HighResMIP. FGOALS-f3-L and FGOALS-f3-H have the same model parameterizations with the exactly the same parameters. The only differences between the two models are the horizontal resolution and the time step. The performance of FGOALS-f3-H and FGOALS-f3-L in simulating tropical cyclones was evaluated using observations. FGOALS-f3$\mathrm{H}$ ( $25 \mathrm{~km}$ resolution) simulated more realistic distributions of the formation, movement and intensity of the climatology of tropical cyclones than FGOALS-f3-L at $100 \mathrm{~km}$ res-
\end{abstract}

olution. Although the number of tropical cyclones increased by about $50 \%$ at the higher resolution and better matched the observed values in the peak month, both FGOALS-f3$\mathrm{L}$ and FGOALS-f3-H appear to replicate the timing of the seasonal cycle of tropical cyclones. The simulated average and interannual variabilities of the number of tropical cyclones and the accumulated cyclone energy were both significantly improved from FGOALS-f3-L to FGOALS-f3-H over most of the ocean basins. The characteristics of tropical cyclones (e.g., the average lifetime, the wind-pressure relationship and the horizontal structure) were more realistic in the simulation using the high-resolution model. The possible physical linkage between the performance of the tropical cyclone simulation and the horizontal resolution were revealed by further analyses. The improvement in the response between the El Niño-Southern Oscillation and the number of tropical cyclones and the accumulated cyclone energy in FGOALS-f3 contributed to the realistic simulation of tropical cyclones. The genesis potential index and the vorticity, relative humidity, maximum potential intensity and the wind 
shear terms were used to diagnose the effects of resolution. We discuss the current insufficiencies and future directions of improvement for the simulation of tropical cyclones and the potential applications of the FGOALS-f3-H model in the subseasonal to seasonal prediction of tropical cyclones.

\section{Introduction}

Tropical cyclones are extreme weather phenomena characterized by intense wind speeds and heavy rainfall. Although tropical cyclones alleviate coastal droughts, they can also cause severe economic losses and significant human casualties (Mendelsohn et al., 2012; Benfield, 2018). Against the current background of global climate change, the effective simulation, prediction and projection of global tropical cyclone activity are challenging but essential for disaster prevention and mitigation (Emanuel, 2017).

The simulation of tropical cyclones in global climate models (GCMs) is challenging in terms of both resolution and physical processes. Tropical cyclone-like structures appeared in early GCMs and Manabe et al. (1970), Bengtsson et al. (1982), Krishnamurti and Oosterhof (1989), Manabe and Broccoli (1990), Wu and Lau (1992) and Haarsma et al. (1993) were pioneers in using objective feature-tracking approaches to study simulated tropical cyclones. However, the low-resolution, incomplete parameterization of the physical processes in these early GCMs meant that their performance in simulating tropical cyclones was limited. For this reason, statistical methods were used to study the climatology of tropical cyclones. Camargo (2013) found that the simulation of the frequency of tropical cyclones in the Coupled Model Intercomparison Project phase 5 (CMIP5) was much lower than in the observations. This was mainly due to the cold biases in the sea surface temperature, which amplified the uncertainty in future projections. Emanuel (2013) designed a downscaling method to reduce the uncertainty in projections of tropical cyclone activity.

The horizontal and vertical resolutions of climate system models have increased over the last few decades, in line with the complex parameterization of the physical processes. As a result, more refined details (e.g., tropical cyclones and tropical waves) can now be resolved. Regional climate system models with smaller spatial scales and lower computing costs can now be used to simulate tropical cyclones. Knutson et al. (2007) used a high-resolution regional model to simulate tropical cyclone activity in the northern Atlantic Ocean. The structure and interannual variability of the simulated tropical cyclones have a high fidelity with the observations. There has also been a significant increase in the resolution of GCMs (Kim et al., 2014; Small et al., 2014; Li and Sriver, 2018; Scoccimarro et al., 2017; Balaguru et al., 2020). Oouchi et al. (2006) used a $20 \mathrm{~km}$ mesh global atmospheric model to simulate tropical cyclone activity in a warming climate and found that the high-resolution GCM could not only describe the details of typhoons very well but also captured the variability of tropical cyclones. Zhao et al. (2009), Knutson et al. (2007), Murakami et al. (2012), Manganello et al. (2012), Strachan et al. (2013) and Zarzycki and Jablonowski (2015) showed that high-resolution GCMs can simulate many of the characteristics of tropical cyclones. The uncertainty in simulating tropical cyclones has been reduced with an increase in resolution, the reasonable parameterization of the physical processes and improvements in the downscaling method (Walsh et al., 2015, 2016; Camargo and Wing, 2016).

The increase in the horizontal resolution of GCMs has led to significant changes in the simulation of the variability of tropical cyclones. The changes can be broadly attributed to two reasons: (1) changes in the large-scale factors; and (2) the development of physical process parameterization and air-sea coupling related to the simulation of tropical cyclones. High-resolution GCMs need to not only give a better description of the structure of tropical cyclones but should also simulate well the relationship between tropical cyclones and large-scale variabilities - for example, the El Niño-Southern Oscillation (ENSO), the Madden-Julian oscillation, wind shear and vorticity, and humidity - which is crucial in reducing the uncertainties in the simulation and prediction of tropical cyclones (Manganello et al., 2012, 2016; Zhang et al., 2016; Delworth et al., 2020). Previous studies have shown that there are significant changes in the ENSO as the horizontal resolution of GCMs increases (Philander et al., 1992; Knutson et al., 1997; Schneider et al., 2003; Masson et al., 2012; Larson and Kirtman, 2013; Meehl et al., 2020) and the simulation results are mostly positive. However, these improvements in predicting the ENSO with an increase in horizontal resolution did not lead to improvements in the relationship between the ENSO and tropical cyclones (Matsuura et al., 1999; Bell et al., 2014; Krishnamurthy et al., 2016). There is also a relationship between the Madden-Julian oscillation and tropical cyclones (Liebmann et al., 1994; Hall et al., 2001; Camargo et al., 2008, 2009; Zhang, 2013; Klotzbach, 2014).

As the horizontal resolution in the models increases, some key parameters in the physical parameterizations are tuned to give a better performance (Bacmeister et al., 2014; Roberts et al., 2020) - for example, Lim et al. (2015) found that an increase in the threshold of minimum entrainment led to increasing tropical cyclone activity and Murakami et al. (2012) found that the constrained convective heating in the convective-scheme-induced intense grid-scale upward motion and promoted large-scale condensation, which favored the development of a more intense tropical cyclone. These artificial tuning methods might introduce more uncertainties in terms of the effects of resolution, giving rise to conclusions that are ambiguous to the tropical cyclone research community. In addition, considering the air-sea coupling process will also affect the simulation performance of tropical cyclone activities, especially with respect to the in- 
tensity. Scoccimarro et al. (2017) found that an increased horizontal resolution of the model components was not sufficient to simulate intense and fast-moving tropical cyclone events and that air-sea coupling with a higher coupling frequency helps to improve the performance of simulations of tropical cyclone intensity.

The impacts of horizontal resolution on the simulation of tropical cyclones were studied using the Chinese Academy of Sciences Flexible Global Ocean-Atmosphere-Land System Finite-Volume version 3 (FGOALS-f3) model, which was developed by the State Key Laboratory of Numerical Modeling for Atmospheric Sciences and Geophysical Fluid Dynamics (LASG), Institute of Atmospheric Physics (IAP). The simulated tropical cyclones in FGOALS-f3 were introduced first, then the outputs of FGOALS-f3-L and FGOALSf3-H were used to reveal the influence of horizontal resolution on these simulations. The latest version of FGOALSf3 participated in the CMIP6 (Eyring et al., 2016), DECK and MIP endorsements (Zhou et al., 2016; He et al., 2019, 2020; Haarsma et al., 2016). FAMIL2 is the atmospheric component of the FGOALS-f3 climate system model. Li et al. (2019) evaluated the simulation performance of tropical cyclone activity in the latest-generation atmospheric general circulation models from the LASG-IAP (Finite-volume Atmospheric Model version 2; FAMIL2) using a coarse resolution with standard AMIP experiments. Although FAMIL2 is able to reproduce many aspects of the activities of tropical cyclones with a horizontal resolution of $1^{\circ}$, there is still some room for improvement in simulating tropical cyclones, such as the weak intensity of tropical cyclones, fewer tropical cyclones in the peak month in the northern Atlantic and eastern Pacific oceans, and inaccurate large-scale factors. Therefore, the the High-Resolution Model Intercomparison Project (HighResMIP) configuration has been applied to both the low- and high-resolution FGOALS-f3. Both model versions retained the exact model physics and parameters and the only differences were the horizontal resolution and model time step, which better meet the rule of HighResMIP: "the experimental set-up and design of the standard-resolution experiments will be exactly the same as for the high-resolution runs". This study aimed to address the following issues: (1) the impacts of horizontal resolution on the simulation of global tropical cyclones in a climate system model; and (2) the possible physical linkages between the horizontal resolution and the simulated tropical cyclones.

This paper is organized as follows. Section 2 introduces the model, data and methods used in this study. Section 3 shows the performance of simulated tropical cyclones in both FGOALS-f3-L and FGOALS-f3-H. Section 4 introduces the possible reasons for the improvement in the simulation of tropical cyclones with an increased horizontal resolution. Section 5 discusses the impact of physical parameterization and air-sea coupling on the simulated tropical cyclones in GCMs, then discusses the potential value-added effect of large-scale factors related to simulated tropical cyclones when the horizontal resolution is increased from the HighResMIP models. Section 6 summarizes our results.

\section{Model, data and methods}

\subsection{Description of FGOALS-f3}

FGOALS-f3 is the latest version of the Chinese Academy of Sciences climate system model and was designed for CMIP6. The FGOALS-f3 model consists of four components: (1) an atmospheric component; (2) an oceanic component; (3) a land surface component; and (4) a sea ice component. The atmospheric component is FAMIL2.2 (Zhou et al., 2015; Bao et al., 2018; Bao and Li, 2020; Li et al., 2019; He et al., 2019), which is the successor to the atmospheric general circulation model of the Spectral Atmosphere Model of LASG (SAMIL) (Wu et al., 1996; Bao et al., 2010, 2013). The oceanic component is the LASG-IAP Climate System Ocean Model version 3 (LICOM3) (Liu et al., 2012). Orthogonal curvilinear coordinates and a tripolar grid are used in LICOM3 and the horizontal resolution can vary flexibly between 1 and $1 / 20^{\circ}$. A new advection scheme has also been updated in LICOM3 (Yu et al., 2018). The land surface component is the Community Land Model version 4.0 (CLM4) (Oleson et al., 2010; Lawrence et al., 2011) with the processes from the dynamic global vegetation model in CLM4.0 used in FGOALS-f3$\mathrm{L} / \mathrm{H}$ turned off. The sea ice component is the Los Alamos Sea Ice Model version 4.0 (CICE 4.0; Hunke et al., 2008; Hunke and Lipscomb, 2010). These four components are coupled by the version 7 coupler in the Community Earth System Model (CESM) (Craig et al., 2012). Li et al. (2019) introduced the atmospheric component FAMIL2 in detail and carried out some tuning to achieve stability in long-term coupled integrations (defined as FAMIL2.2).

Table 1 shows that the finite-volume cubed-sphere dynamical core (FV3) (Lin, 2004; Putman and Lin, 2007; Voosen, 2017) is used as the dynamical core in FAMIL2.2. The University of Washington moist turbulence parameterization (Park and Bretherton, 2009) is also used in FGOALS-f3. This is a non-local, high-order closure scheme and uses the diagnosed turbulent kinetic energy to determine the eddy diffusivity in turbulence. The resolving convective precipitation (RCP) parameterization (Bao and Li, 2020) is used, which involves calculating the microphysical processes in the cumulus scheme for both deep and shallow convection; six species are considered, similar to the Geophysical Fluid Dynamics Laboratory (GFDL) cloud microphysics scheme (Zhou et al., 2019). The gravity wave drag scheme (Palmer et al., 1986), the cloud fraction diagnosis scheme (Xu and Randall, 1996) and the radiative transmission scheme (Clough et al., 2005) are also considered.

The vertical layers of FGOALS-f3-L and FGOALS-f3$\mathrm{H}$ are both set to 32 , whereas the horizontal resolutions of FGOALS-f3-L and FGOALS-f3-H are C96 (about $100 \mathrm{~km}$ ) 
Table 1. Dynamical core and physics parameterization schemes used in FGOALS-f3.

\begin{tabular}{ll}
\hline Model configuration & FGOALS-f3 \\
\hline Dynamical core & Finite-volume cubed-sphere dynamical core \\
Boundary layer scheme & University of Washington moist turbulence parameterization (Park and Bretherton, 2009) \\
Radiation scheme & Rapid Radiative Transfer Model for GCMs (Clough et al., 2005) \\
Gravity wave drag scheme & Palmer et al. (1996) \\
Cloud fraction diagnosis scheme & Xu and Randall (1996) \\
Convection microphysics scheme & Resolving convective precipitation (Bao and Li, 2020) \\
\hline
\end{tabular}

and C384 (about $25 \mathrm{~km}$ ), respectively (Table 2). To maintain the stability of the integration for the dynamical core, the two parameters (k_split and n_split) included in FV3 are different in FGOALS-f3-L and FGOALS-f3-H. k_split is the number of vertical remapping operations per physical time step in the dynamical integration and $\mathrm{n} \_$split is the number of small dynamic (acoustic) time steps between the vertical remapping operations, which will affect the stability of the integration when the horizontal resolution of the model is changed. Considering that FGOALS- $\mathrm{f} 3-\mathrm{H}$ requires more frequent vertical remapping, $\mathrm{k} \_$split and n_split are set to 6 and 15, respectively (they are 2 and 6, respectively, in FGOALS-f3-L). The time steps of the physical processes are both set to $30 \mathrm{~min}$, but the update frequency of radiative transmission and the minimum time step of the microphysics scheme in both FGOALS-f3-L and FGOALS-f3-H are $1 \mathrm{~h}$ and $150 \mathrm{~s}$, respectively. Li et al. (2017) tested the computing performance between FGOALS-f3-L and FGOALS-f3-H using the Tianhe- 2 supercomputer and the results indicated a high computing speed-up and low computing costs when the number of parallel processes was increased.

\subsection{Datasets}

FGOALS-f3 participated in CMIP6 DECK (Eyring et al., 2016), the Global Monsoons Model Intercomparison Project (GMMIP; Zhou et al., 2016; He et al., 2019) and HighResMIP (Haarsma et al., 2016). The datasets from CMOR for the CMIP6 HighResMIP are in a standard format. The experimental design satisfies the requirement for HighResMIP Tier 1. Two resolutions of FGOALS-f3 are used to compare the simulation of tropical cyclone activities at different resolutions. To identify the impact of resolution, there was no tuning of the parameterization of the physical processes between FGOALS-f3-L and FGOALS-f3-H. The time period 1991-2014 is extracted to avoid the uncertainties in the presatellite era in the observations.

The International Best Track Archive for Climate Stewardship v03r10 (IBTrACS; Knapp et al., 2010) is used as the observational dataset. IBTrACS is a multisource dataset and includes the RSMC Tokyo, Chinese Meteorological Administration-Shanghai Typhoon Institute (Ying et al., 2014) and the National Hurricane Center data sources. To provide a fair comparison, transformation from the $10 \mathrm{~min}$ - averaged maximum sustained wind to the 1 min-averaged maximum sustained wind is needed and the relevant coefficient is set to 0.88 (Manganello et al., 2012; Knapp et al., 2010; Li et al., 2019). The European Centre for MediumRange Weather Forecasts ERA-Interim reanalysis dataset (Dee et al., 2011) (resolution $0.75^{\circ}$ ), the National Centers for Environmental Prediction Global Forecast System (GFS) reanalysis dataset (resolution $0.25^{\circ}$ ) and the Global Precipitation Measurement (GPM) dataset (resolution $0.25^{\circ}$ ) (Hou et al., 2014) for the time period 1991-2014 are used as the observations to quantitatively evaluate the tropical cyclones simulated in FGOALS-f3.

\subsection{Tracking algorithms}

An objective feature-tracking approach is used to detect the model-generated tropical cyclones based on the $6 \mathrm{~h}$ outputs of FGOALS-f3-L and FGOALS-f3-H. According to the tracking scheme (Table 3), the sea-level pressure, warm core (the temperature anomaly averaged between 300 and $500 \mathrm{hPa}$ ), $10 \mathrm{~m}$ wind and the $850 \mathrm{hPa}$ absolute vorticity are used to diagnose the tropical cyclone activity, which is similar to the method used in the climate system model of the GFDL (Zhao et al., 2009; Chen and Lin, 2013; Xiang et al., 2015). Li et al. (2019) used this scheme to evaluate the simulated performance of tropical cyclones in FAMIL2 and showed a consistent performance. The wind speed thresholds between FGOALS-f3-L and FGOALS-f3-H are consistent with the relationship between the horizontal resolution of the models and the tropical cyclone detection algorithms (Walsh et al., 2007).

\section{Results}

\subsection{Global climatology of tropical cyclone track density}

The climatology of simulated tropical cyclones is the first step in testing the performance of the model. Zhao et al. (2009) used a GFDL GCM with a $50 \mathrm{~km}$ horizontal resolution to simulate global tropical cyclone activity and obtained a negative bias in the number of tropical cyclones in the eastern Pacific, northern Atlantic and southern Indian oceans. These biases also appeared in the low-resolution 
Table 2. Comparison of resolutions, time steps and length of simulations in FGOALS-f3 for HighResMIP Tier 1.

\begin{tabular}{lll}
\hline Model configuration & 100 km FGOALS-f3 & 25 km FGOALS-f3 \\
\hline Horizontal resolution & C96 (about 100 km) & C384 (about 25 km) \\
\hline Number of vertical layers & 32 & 32 \\
\hline $\begin{array}{l}\text { Number of vertical remapping operations per physical } \\
\text { time step with dynamical integration (k_split) }\end{array}$ & 2 & 6 \\
\hline $\begin{array}{l}\text { Number of small dynamic time steps between the verti- } \\
\text { cal remapping operations (n_split) }\end{array}$ & 6 & 15 \\
\hline Time step of dynamical core (min) & 30 & 30 \\
\hline Time step of physical processes (min) & 30 & 30 \\
\hline Frequency of radiative transmission (h) & 1 & 1 \\
\hline Minimum time step of microphysics scheme (s) & 150 & 150 \\
\hline Length of simulations & $1950-2014$ & $1950-2014$ \\
\hline
\end{tabular}

Table 3. Comparison of tropical cyclone identification criterion between FGOALS-f3-L and FGOALS-f3-H.

\begin{tabular}{lll}
\hline Variable & FGOALS-f3-L & FGOALS-f3-H \\
\hline Surface wind speed threshold $\left(\mathrm{m} \mathrm{s}^{-1}\right)^{*}$ & $\geq 14.0$ & $\geq 15.4$ \\
$850 \mathrm{hPa}$ absolute vorticity $\left(\mathrm{s}^{-1}\right)$ & $\geq 3.5 \times 10^{-5}$ & $\geq 3.5 \times 10^{-5}$ \\
Warm core (average temperature between 300 and $500 \mathrm{hPa}\left({ }^{\circ} \mathrm{C}\right)$ & $\geq 1$ & $\geq 1$ \\
Lifetime (h) & $\geq 72$ & $\geq 72$ \\
\hline
\end{tabular}

* The criteria for the surface wind speed were corrected between FGOALS-f3-L and FGOALS-f3-H (Walsh et al., 2007).

models participating in the US Climate Variability and Predictability (CLIVAR) Working Group on Hurricanes (Walsh et al., 2015). Figure 1a and $\mathrm{b}$ show the tracks and intensities of global tropical cyclones in the FGOALS-f3-L and FGOALS-f3-H simulations, respectively. The definition of the intensity follows the Saffir-Simpson intensity scale (Simpson and Saffir, 1974). The negative biases of the tracks of tropical cyclones in FGOALS-f3-L (Fig. 1a) improve when the horizontal resolution increases from 100 to $25 \mathrm{~km}$ (Fig. 1b) relative to IBTrACS. Table 4 shows the observed and simulated average number of tropical cyclones, both globally and by ocean basin. The results in Table 4 indicate that the value-added effect of tropical cyclone counts from the increased horizontal resolution is seen globally.

The improvement is also clearly shown in Fig. 2, and the differences in track densities between FGOALS-f3-H and FGOALS-f3-L reflect a positive distribution in the global basin (Fig. 2c). The biases in the track densities between the simulation and IBTrACS are improved when the horizontal resolution is increased from $100 \mathrm{~km}$ (Fig. 2a) to $25 \mathrm{~km}$ (Fig. 2b), especially in the low-latitude basins where tropical cyclones form. Negative biases between FGOALS-f3-L and IBTrACS appear in the midlatitudes of the western Pacific and northern Atlantic oceans, but positive biases between the FGOALS-f3-H and IBTrACS also appear in these areas, which means that there are more tropical cyclone events at higher latitudes in FGOALS-f3-H than in IBTrACS and the simulation in FGOALS-f3-L. This phenomenon also exists in the high-resolution GCMs that participated in the European Union Horizon 2020 project PRIMAVERA (Roberts et al., 2020). The biases in the large-scale factors (e.g., strong steering flow) related to the tropical cyclones in GCMs may lead to the simulated biases of tropical cyclone activities in the western Pacific and northern Atlantic oceans.

The negative biases in the intensities of tropical cyclones are also improved when the horizontal resolution is increased from $100 \mathrm{~km}$ (Fig. 1a) to $25 \mathrm{~km}$ (Fig. 1b), especially in the western Pacific and northern Atlantic oceans. The difference in wind speed densities between FGOALS-f3-L and FGOALS-f3-H (Fig. 3c) shows a significant increase in the wind speed densities in the northern Atlantic, eastern Pacific and northern Indian oceans and the midlatitude region of the western Pacific Ocean when the horizontal resolution is increased from 100 to $25 \mathrm{~km}$. Similar to the pattern of track density anomalies (Fig. 2), the biases in the wind speed densities between FGOALS-f3 and IBTrACS are improved when the horizontal resolution is increased from 100 to $25 \mathrm{~km}$, but the positive biases are intensified in the midlatitudes of the western Pacific and northern Atlantic oceans. 
Table 4. Observed and simulated average tropical cyclone number, both globally and by ocean basin, in the northern Indian (NI), western Pacific (WP), eastern Pacific (EP), northern Atlantic (NA), southern Indian Ocean (SI), southern Pacific (SP) and southern Atlantic (SA) oceans.

\begin{tabular}{lcccrrrrc}
\hline Data source & Global & NI & WP & EP & NA & SI & SP & SA \\
\hline IBTrACS & 82.67 & 4.05 & 26.24 & 15.00 & 13.85 & 14.25 & 9.14 & 0.14 \\
FGOALS-f3-L & 53.14 & 1.98 & 25.04 & 3.96 & 7.54 & 7.34 & 6.83 & 0.45 \\
FGOALS-f3-H & 67.72 & 3.25 & 27.46 & 10.00 & 11.83 & 8.63 & 6.09 & 0.46 \\
\hline
\end{tabular}

(a) $100 \mathrm{~km}$ FGOALS-f simulation during 1991-2014

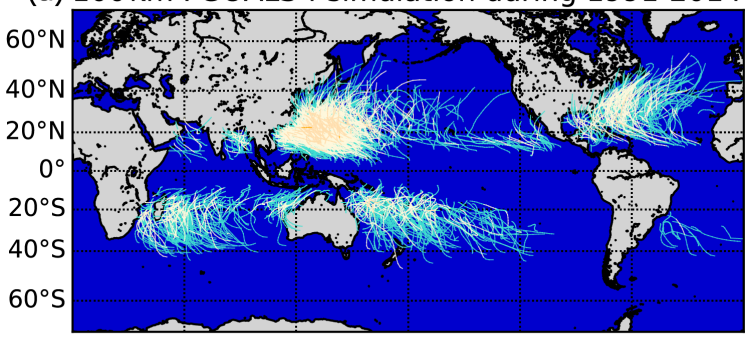

(b) $25 \mathrm{~km}$ FGOALS-f simulation during 1991-2014

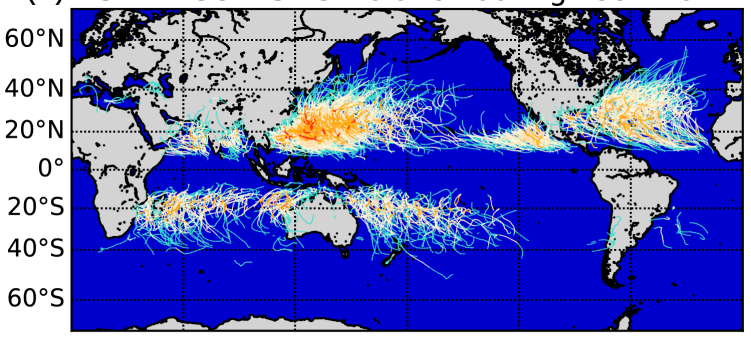

(c)

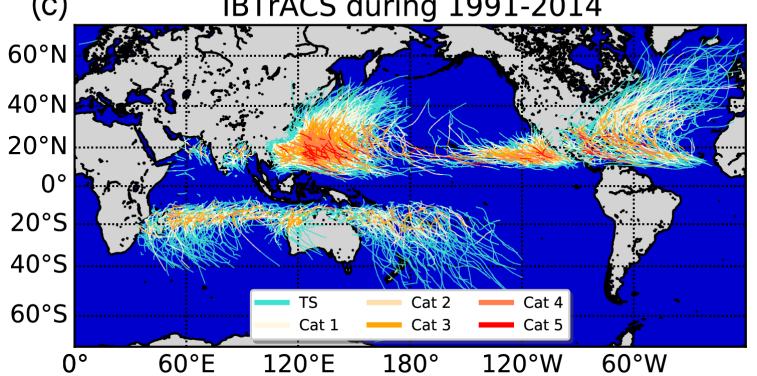

Figure 1. Global tropical cyclone tracks (lines) and intensities (colors) during the time period 1991-2014 between (a) FGOALS-f3-L, (b) FGOALS-f3-H and (c) IBTrACS. The tropical cyclones simulated by FGOALS-f3-L/H are picked out using an objective featuretracking approach, and only those tropical cyclones with a lifetime $>3 \mathrm{~d}$ are shown. The definition of intensity threshold is consistent with the Saffir-Simpson scale: TS, tropical storm; Cat 1-5, category $1-5$.

Figure 4 shows the pressure-wind pairs for each 6-hourly measurement of tropical cyclones between FGOALS-f3 and IBTrACS. The results indicate that the simulated intensity of tropical cyclones is increased globally. These results also indicate that the spread of pressure-wind pairs in FGOALS$\mathrm{f3}-\mathrm{L}$ is narrow and there is a severe underestimation of intense tropical cyclone events at lower surface pressures and
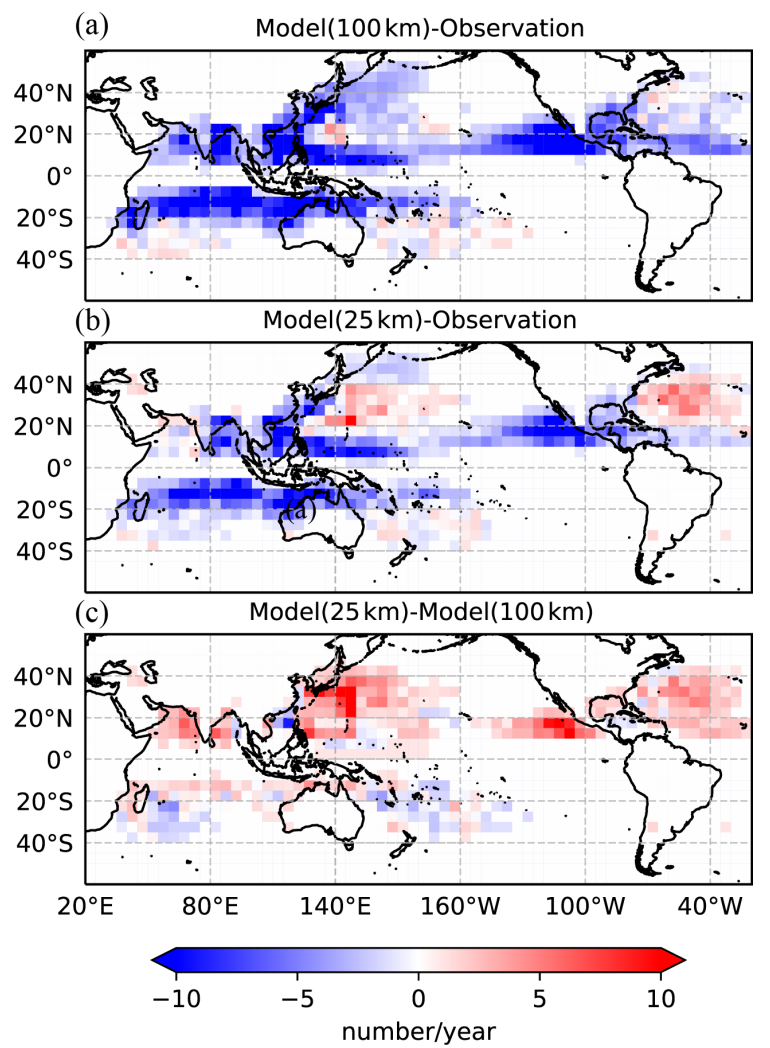

Figure 2. Global track density anomalies of tropical cyclones. The track density is analyzed in $\left(5^{\circ} \times 5^{\circ}\right)$ equidistant grid boxes at $6 \mathrm{~h}$ intervals and the unit of the color map is the number of cyclones per year from 1991 to 2014. (a) Track density anomaly between FGOALS-f3-L and IBTrACS; (b) track density anomaly between FGOALS-f3-H and IBTrACS; and (c) track density anomaly between FGOALS-f3-H and FGOALS-f3-L.

higher wind speeds in the western Pacific and northern Atlantic oceans, although this bias has been dramatically improved (Fig. 4b, d).

The increased intensity of tropical cyclones in FGOALSf3-H favors the apparent negative bias of the lifetime of tropical cyclones in FGOALS-f3-L when the horizontal resolution is increased. Figure 5 shows the average lifetime of tropical cyclones from 1991 to 2014. The average lifetime of tropical cyclones in the observations is about 8.5, 7.5, 7.5, 4, 6.1 and $7.5 \mathrm{~d}$ in the western Pacific, northern Atlantic, eastern Pa- 

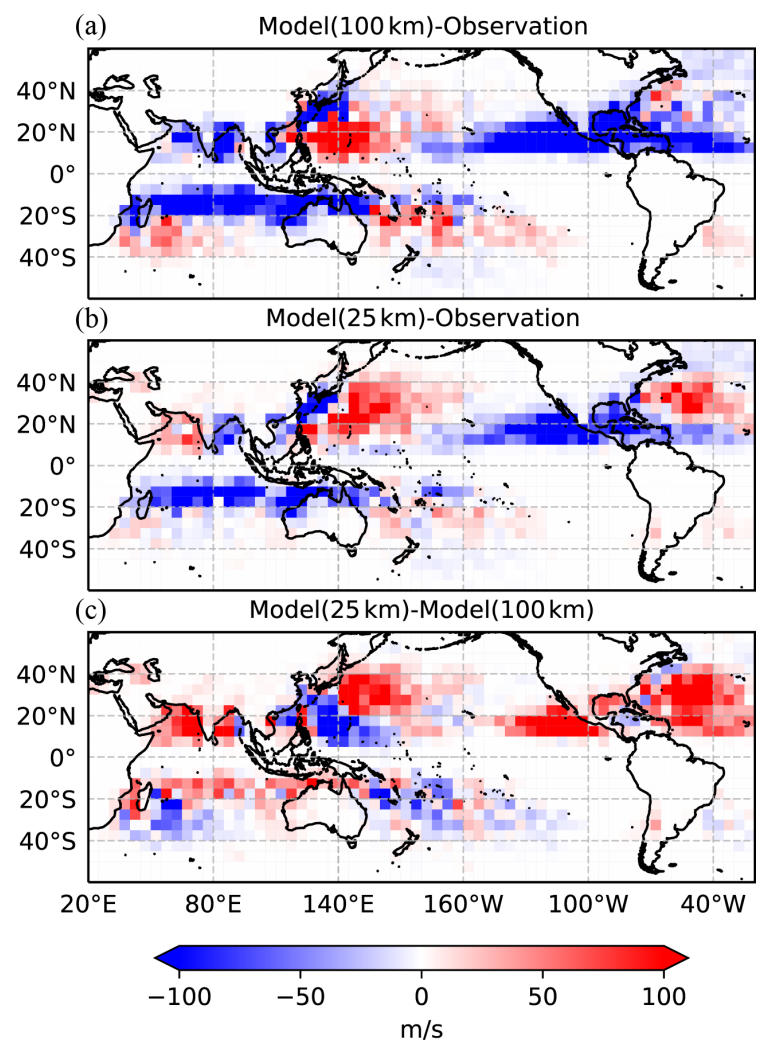

Figure 3. Global maximum sustained wind anomalies of the tropical cyclones (units: $\mathrm{ms}^{-1}$ ). The track density is analyzed in $\left(5^{\circ} \times 5^{\circ}\right)$ equidistant grid boxes at $6 \mathrm{~h}$ intervals. (a) Maximum sustained wind anomalies between FGOALS-f3-L and IBTrACS; (b) maximum sustained wind anomalies between FGOALS-f3-H and IBTrACS; and (c) maximum sustained wind anomalies between FGOALS-f3-H and FGOALS-f3-L.

cific, northern Indian, southern Indian and southern Pacific oceans, respectively, and the simulation of the average lifetime of tropical cyclones is increased in these six basins when the horizontal resolution is increased from 100 to $25 \mathrm{~km}$. For example, the simulated average lifetime of tropical cyclones increases from 6 to $7.4 \mathrm{~d}$ when the horizontal resolution is increased in the western Pacific Ocean.

\subsection{Seasonal cycles, interannual variability and accumulated cyclone energy of tropical cyclones}

Evaluating the seasonal cycle and interannual variability of tropical cyclones in GCMs is an efficient way to verify the coordination between tropical cyclone activity and largescale circulation patterns (Manganello et al., 2012; Camargo and Wing, 2016; Knutson et al., 2019, 2020). Roberts et al. (2020) found no uniform improvement in the seasonal cycle and interannual variability of tropical cyclones at increased horizontal resolutions, which means that there is a difference in coordination between tropical cyclone activity and large-scale circulation patterns in high-resolution
GCMs. Figure 6 shows the seasonal cycle of tropical cyclones between IBTrACS, FGOALS-f3-L and FGOALS-f3$\mathrm{H}$ and shows that FGOALS-f3-L gives a consistent underestimation of the seasonal cycle of tropical cyclones in the northern Atlantic, eastern Pacific, northern Indian, southern Indian and southern Pacific oceans. Neither the single peak in the number of tropical cyclones in the northern Atlantic (peak month September), eastern Pacific (peak month August) and southern Pacific (peak month February) oceans nor the double peak in the northern Indian Ocean (peak months May and November) could be reproduced in FGOALS-f3-L. There are two increases in the simulated number of tropical cyclones in the peak months of the northern Atlantic and eastern Pacific oceans, and the characteristics of the seasonal cycle of simulated tropical cyclones are improved in the northern Indian, western Pacific and southern Pacific oceans as the horizontal resolution is increased from 100 to $25 \mathrm{~km}$. Although FGOALS-f3-H can produce more tropical cyclone counts in the peak month in each basin, both FGOALS-f3-L and FGOALS-f3-H appeared to replicate the timing of the seasonal cycle when we normalized the results of the tropical cyclone seasonal cycle (Fig. A1). Figure 7 shows the interannual correlation of the number of tropical cyclones between FGOALS-f3 and IBTrACS. The results show that the correlation coefficient is improved in each basin, which reflects the fact that the interannual variability between tropical cyclone activity and large-scale circulation patterns is harmonious.

Table 5 shows the observed and simulated averaged accumulated cyclone energy (ACE; Bell and Chelliah, 2000). ACE is a measure used by the National Oceanic and Atmospheric Administration in which the energy over the lifetime of a tropical cyclone is calculated for every $6 \mathrm{~h}$ period:

$\mathrm{ACE}=10^{-4} \sum V_{\mathrm{m}}^{2}$,

where $V_{\mathrm{m}}$ is the estimated sustained wind speed in knots.

Our results indicate that the negative biases of the ACE in FGOALS-f3-L are improved globally when the horizontal resolution is increased to $25 \mathrm{~km}$. Figure 8 shows the interannual correlation of the ACE between FGOALS-f3 and IBTrACS. The results show that the correlation coefficient of the ACE between IBTrACS and the simulation is improved in each basin when the horizontal resolution is increased from 100 to $25 \mathrm{~km}$. The increase in the number, lifetime and intensity of simulated tropical cyclones contributes to the increased correlation coefficient of the ACE (Camargo and Sobel, 2005).

\subsection{Horizontal structure of tropical cyclones}

Previous studies have shown that the horizontal resolution influences the horizontal structure of simulated tropical cyclones (Strachan et al., 2013; Murakami et al., 2012, 2013; Roberts et al., 2020). Manganello et al. (2012) compared the horizontal structure of the moisture content of tropical cyclones in GCMs between low (T511) and high (T2047) 

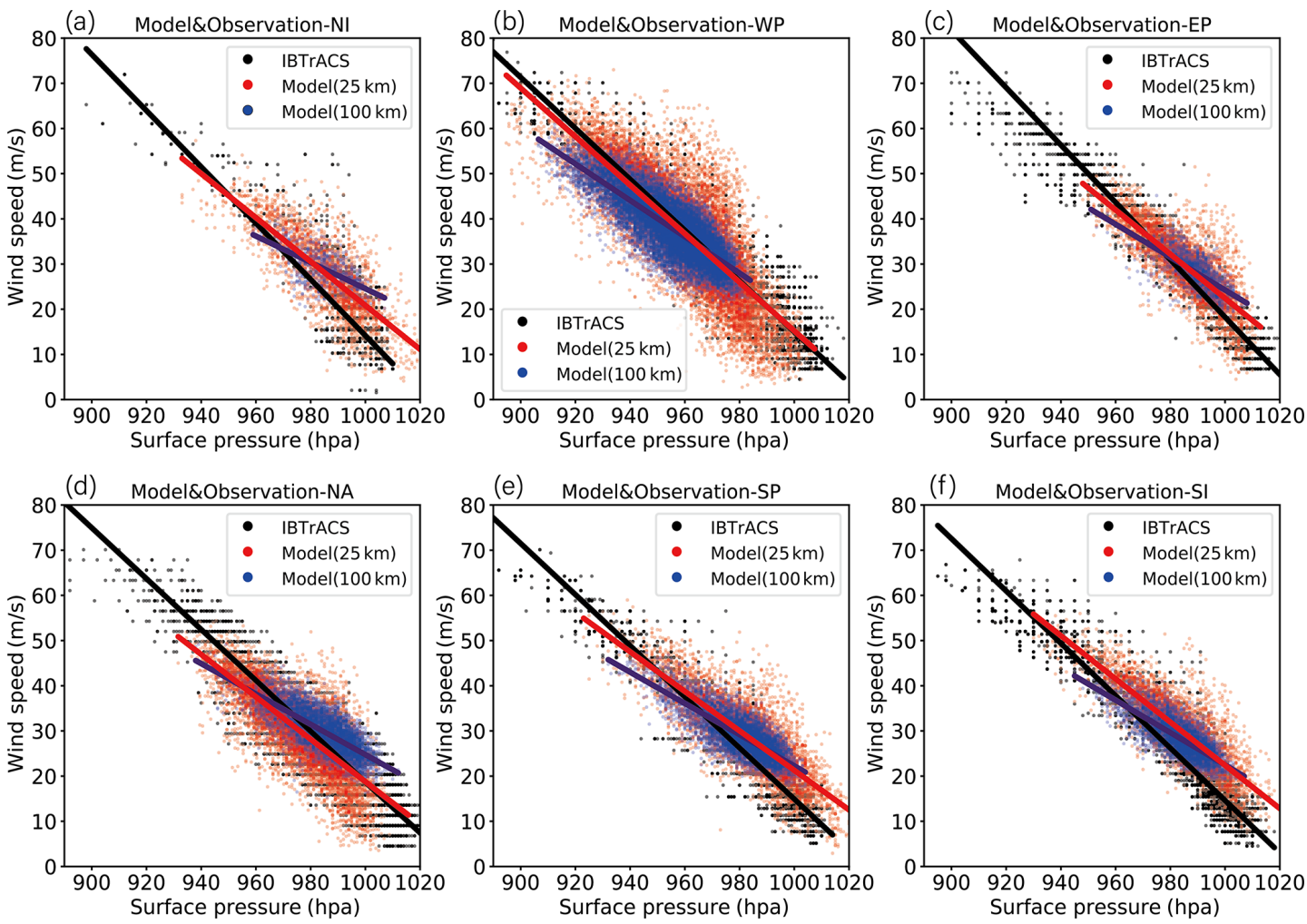

Figure 4. Pressure-wind pairs for each 6-hourly tropical cyclone measurement for FGOALS-f3-L (blue dots) and FGOALS-f3-H (red dots) and IBTrACS (black dots) in the (a) northern Indian Ocean, (b) western Pacific, (c) eastern Pacific, (d) northern Atlantic, (e) southern Pacific and (f) southern Indian oceans. A linear regression (blue/red line for FGOALS-f3-L/H; black line for IBTrACS) is fitted to each distribution of pressure-wind pairs.

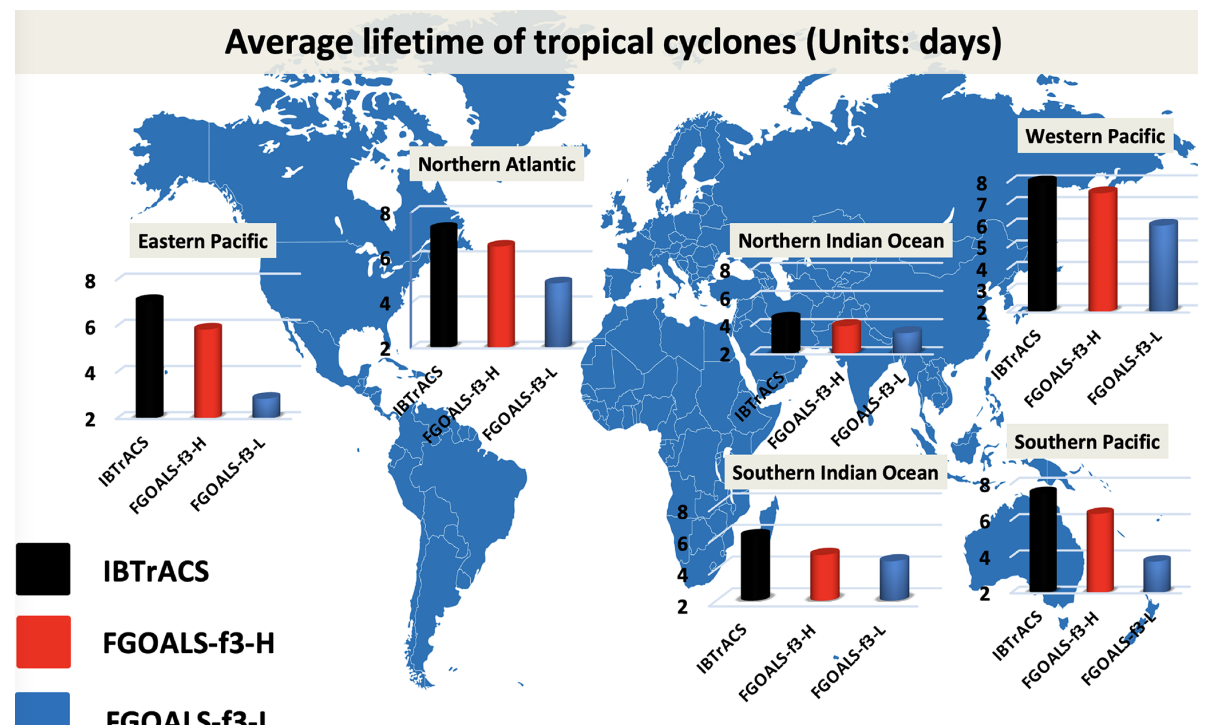

Figure 5. Climatological lifetime of tropical cyclones in the western Pacific, southern Pacific, northern Indian, northern Atlantic, eastern Pacific oceans and southern Indian oceans (units: d) during the time period 1991-2014. 


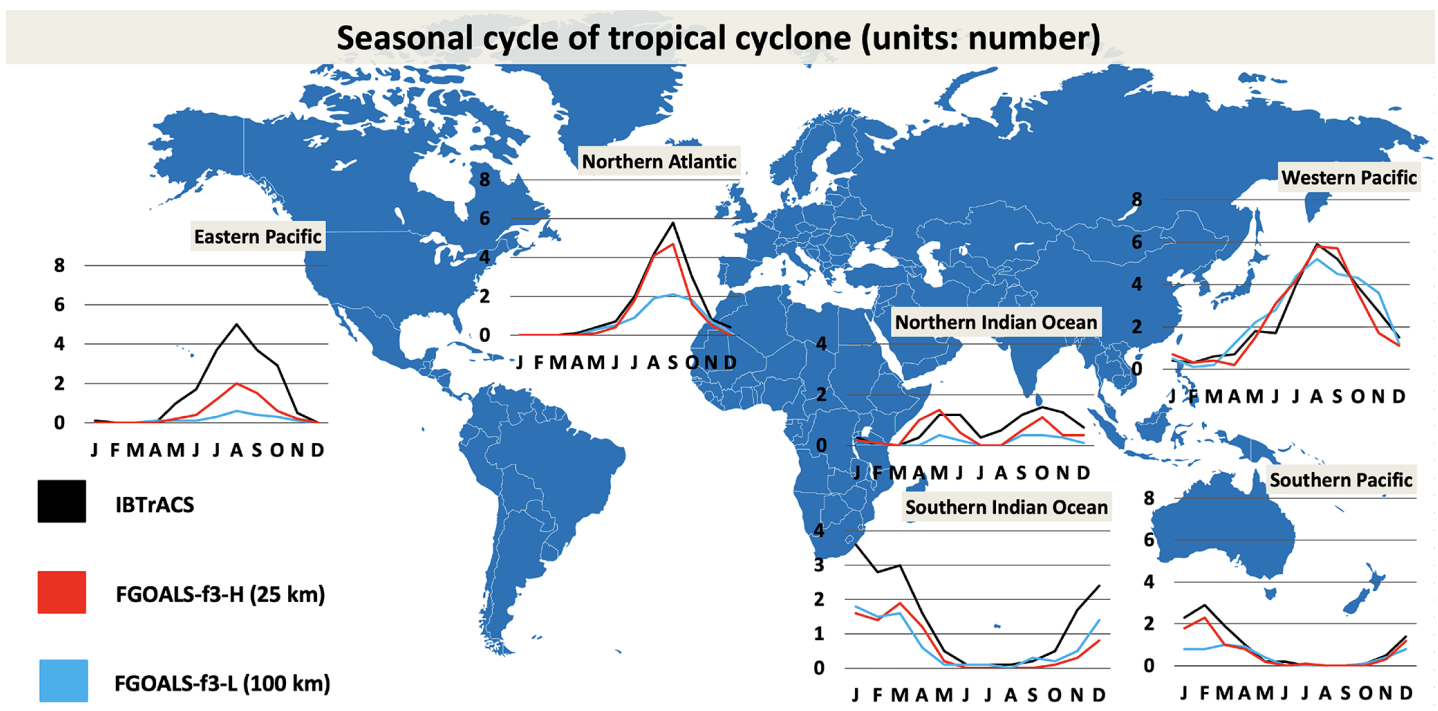

Figure 6. Seasonal cycle of tropical cyclones in the western Pacific, southern Pacific, northern Indian, northern Atlantic, eastern Pacific and southern Indian oceans (units: number of cyclones) during the time period 1991-2014.

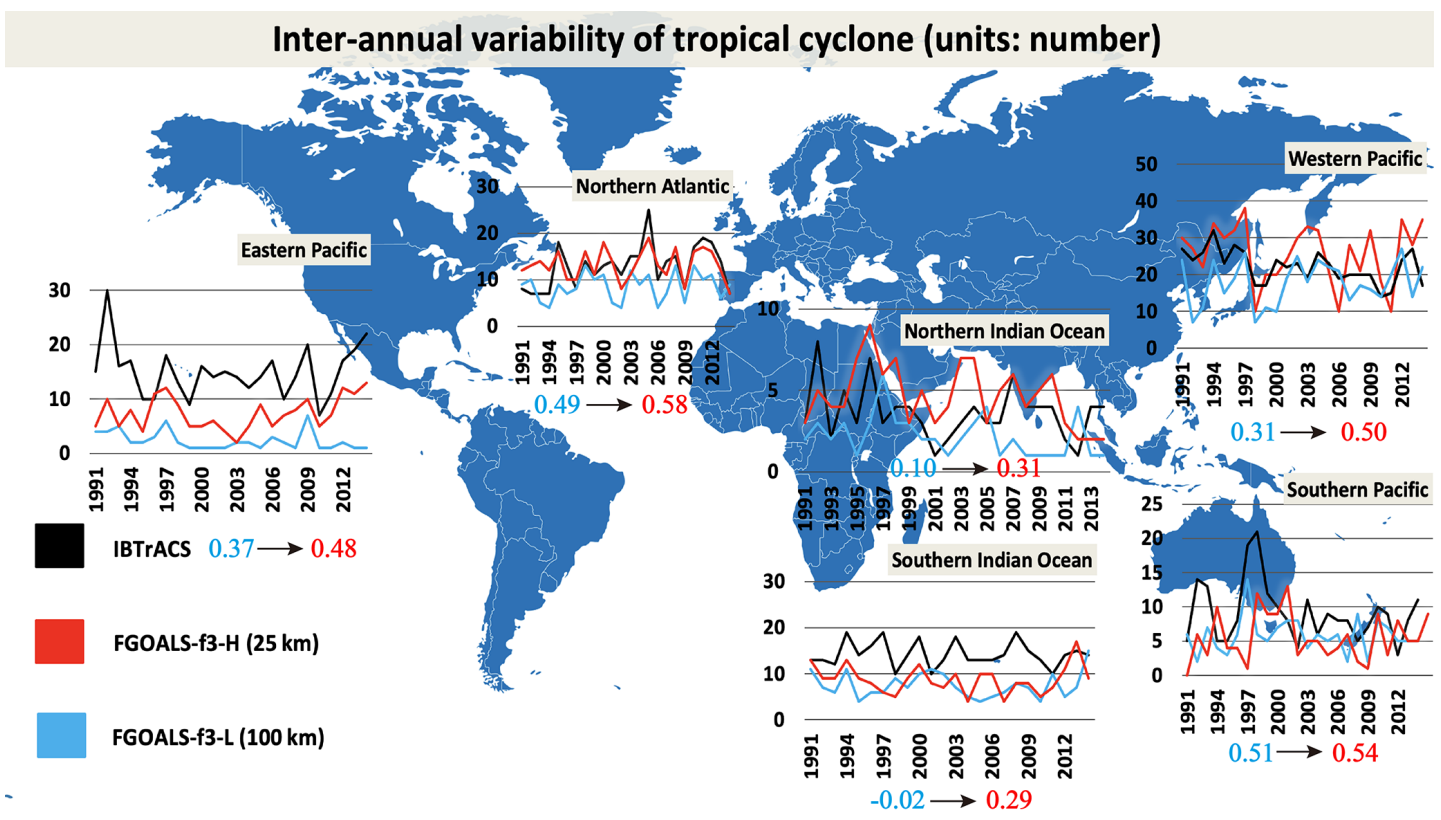

Figure 7. Interannual variability of tropical cyclones in the western Pacific, southern Pacific, northern Indian, northern Atlantic, eastern Pacific and southern Indian oceans (units: number of cyclones) during the time period 1991-2014. The numbers under the line charts are the correlation coefficients between IBTrACS and FGOALS-f3.

resolutions and found that the refined structure of the liquid component of tropical cyclones was simulated when the horizontal resolution was increased. Following the method of Manganello et al. (2012), the surface $10 \mathrm{~m}$ wind and daily precipitation rate for the 30 most intense tropical cyclones in FGOALS-f3-L (Fig. 9a) and FGOALS-f3-H (Fig. 9b) were combined. The results of the GFS (Fig. 9c) and the GFS and GPM (Fig. 9d) simulations are also shown for comparison.
The results indicate that there is no prominent precipitation structure of tropical cyclones in FGOALS-f3-L, but there is a considerable improvement in the results with a horizontal resolution of $25 \mathrm{~km}$. The eyewall and organized precipitation of tropical cyclones are apparent in the FGOALS-f3-H simulation. The main uncertainty is the position of extreme precipitation. The position of extreme precipitation appears $100 \mathrm{~km}$ east of the eyewall in the FGOALS-f3-H simulation 
Table 5. Observed and simulated averaged ACE (units: $10^{4} \mathrm{kt}$ ) in the northern Indian (NI), western Pacific (WP), eastern Pacific (EP), northern Atlantic (NA), southern Indian (SI) and southern Pacific (SP) oceans.

\begin{tabular}{lccrrrc}
\hline Data source & NI & WP & EP & NA & SI & SP \\
\hline IBTrACS & 24.21 & 258.75 & 137.42 & 133.13 & 114.25 & 67.58 \\
FGOALS-f3-L & 12.13 & 170.47 & 7.83 & 69.38 & 50.50 & 60.30 \\
FGOALS-f3-H & 32.08 & 247.66 & 43.66 & 89.10 & 68.16 & 61.21 \\
\hline
\end{tabular}

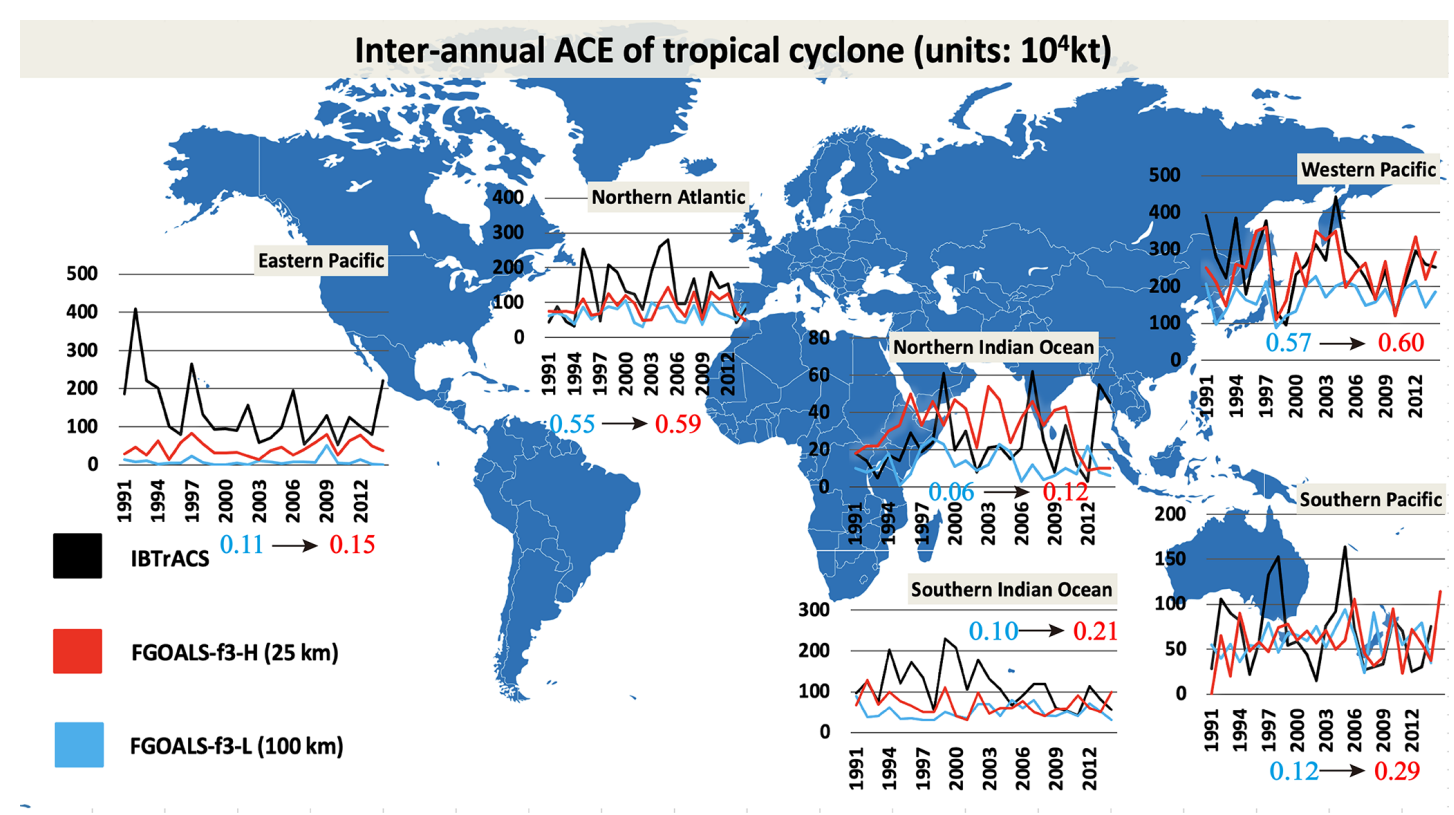

Figure 8. ACE of tropical cyclones (units: $10^{4} \mathrm{kt}$ ) in the western Pacific, southern Pacific, northern Indian, northern Atlantic, eastern Pacific, and southern Indian oceans (units: number of cyclones) during the time period 1991-2014.

(Fig. 9b) but is $100 \mathrm{~km}$ south of the eyewall in the GFS and GPM datasets (Fig. 9c). There is an apparent error in the angle compared with the radial distance for the simulated horizontal structure of tropical cyclones. Chen et al. (2006) found that the vertical wind shear and storm motion are the two most important factors contributing to rainfall asymmetries in tropical cyclones. The biases in the vertical wind shear and storm motion in FGOALS-f3 may affect the angle of the horizontal structure of tropical cyclones. The non-hydrostatic dynamical core used in FGOALS-f3 and the limited air-sea coupling processes (Emanuel and Sobel, 2013; Kim et al., 2018) (AMIP) also contribute to the error.

\section{Possible reasons for the simulated performance of tropical cyclones in FGOALS-f3}

\subsection{Modulation of tropical cyclone activity by the ENSO}

There is a lot of evidence to suggest that the ENSO modulates the activity of tropical cyclones. Gray (1984) found that tropical cyclone counts in the Atlantic Ocean are modulated by the ENSO. El Niño (La Niña) events enhanced (suppressed) westerly winds and led to stronger (weaker) vertical wind shear in the Atlantic basin, leading to an increase (decrease) in tropical cyclone counts. Camargo and Sobel (2005) found that the ACE in the western Pacific is positively correlated with ENSO indices. There are more intense and longer-lived tropical cyclones in El Niño years than in La Niña years. Kim et al. (2011) found that the ENSO modulates tropical cyclone activity in the eastern Pacific Ocean. The track densities and genesis of tropical cyclones tend to be enhanced (suppressed) in eastern Pacific warming (cooling) years by strong (weak) westerly wind shear.

Figure 10 shows the average number of tropical cyclones and the ACE from El Niño, neutral and La Niña years. In the western Pacific basin (Fig. 10a), there is no clear change in tropical cyclone counts compared with the variation of the ACE between El Niño and La Niña years. FGOALS-f3-H can capture these features in the observations; in particular, the simulation of the ACE is better than in FGOALS-f3-L. In the eastern Pacific basin (Fig. 10b), FGOALS-f3 can capture the variation in tropical cyclone activities from El Niño to La Niña years, but the decreasing trend of tropical cy- 


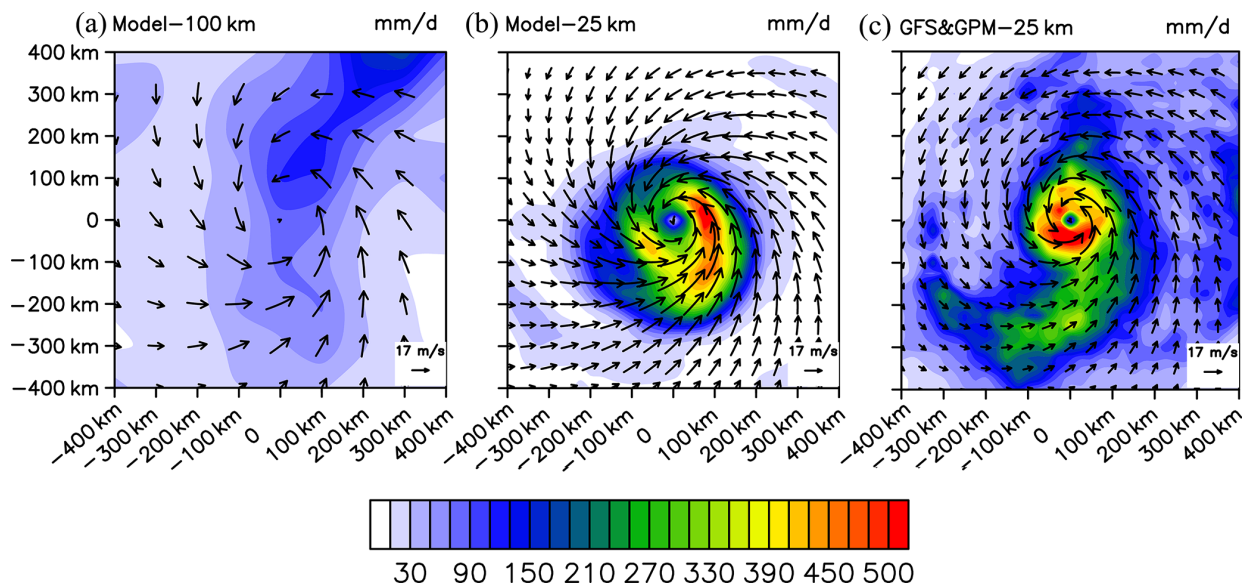

Figure 9. Surface $10 \mathrm{~m}$ winds (units: $\mathrm{m} \mathrm{s}^{-1}$ ) and daily precipitation rate $\left(\mathrm{mm} \mathrm{d}^{-1}\right)$ for the horizontal composite of the $30 \mathrm{most}$ intense tropical cyclones in (a) FGOALS-f3-L and (b) FGOALS-f3-H. (c) Results of the surface $10 \mathrm{~m}$ wind in GFS and the daily precipitation rate in GPM. Radius is $4^{\circ}$.

clone counts and the ACE in FGOALS-f3-L/H is weaker than in the observations. In the observations for the northern Atlantic basin (Fig. 10c), there are more intense tropical cyclone events in La Niña years. FGOALS-f3 can reproduce the impact of the ENSO on tropical cyclone activity in the northern Atlantic Ocean and the simulated performance of tropical cyclones in FGOALS-f3-H is better than that in FGOALS-f3-L.

\subsection{Large-scale environmental factors}

The genesis potential index (GPI; Emanuel et al., 2004) is applied to detect the connection between the genesis of tropical cyclones and large-scale circulation patterns. Camargo et al. (2007) and Walsh et al. (2013) found that the correlation between the GPI and the variation of tropical cyclones in GCMs mainly depends on the horizontal resolution and the similarity between the GPI. The variation in tropical cyclones is increased when the horizontal resolution is increased. The GPI used in this work is defined as

$\mathrm{GPI}=\mid 10^{5}$ vort $\left.850\right|^{3 / 2}\left(\frac{\mathrm{RH}}{50}\right)\left(\frac{V_{\mathrm{m}}}{70}\right)\left(1+0.1 V_{\text {shear }}\right)^{-2}$,

where vort850 is the $850 \mathrm{hPa}$ absolute vorticity $\left(\mathrm{s}^{-1}\right), \mathrm{RH}$ is the $600 \mathrm{hPa}$ relative humidity (\%), $V_{\mathrm{m}}$ is the maximum potential intensity (Emanuel, 1995), and $V_{\text {shear }}$ is the magnitude of the wind shear between 850 and $200 \mathrm{hPa}\left(\mathrm{m} \mathrm{s}^{-1}\right) . V_{\mathrm{m}}$ (the maximum potential intensity) is defined here as

$V_{\mathrm{m}}=\frac{C_{\mathrm{k}} T_{\mathrm{s}}}{C_{\mathrm{d}} T_{0}}\left(\mathrm{CAPE}^{*}-\mathrm{CAPE}^{\mathrm{b}}\right)$

where $C_{\mathrm{k}}$ is the exchange coefficient of the enthalpy, $C_{\mathrm{d}}$ is the drag coefficient, $T_{\mathrm{S}}$ is the sea surface temperature, and $T_{0}$ is the mean outflow temperature. CAPE* is the convective available potential energy of the air lifted from saturation at sea level and $\mathrm{CAPE}^{\mathrm{b}}$ is the convective available potential energy of the boundary layer air.

Figure 11 shows the biases of the large-scale environmental factors related to tropical cyclone activity between FGOALS-f3 and the observations. The results indicate that the biases in the large-scale environmental factors are decreased in FGOALS- $\mathrm{f} 3$ when horizontal resolution is increased from 100 to $25 \mathrm{~km}$, which is related to the biases in the simulated tropical cyclones. For example, the environmental vertical wind shear (VWS) is known to be one of the major factors in the generation and intensity of tropical cyclones (Gray, 1968; Wong and Chan, 2004). An excessive VWS in the eastern Pacific and northern Atlantic oceans can lead to the suppression of the generation and intensity of simulated tropical cyclones in these basins (Fig. 11e), which is consistent with the results for the simulation of tropical cyclones in FGOALS-f3-L (Fig. 3). The results in Fig. 12 show the pattern correlation of each individual part of the GPI. P1 represents the equation $\mid 10^{5}$ vort850 $\left.\right|^{3 / 2}$, P2 represents the equation $\frac{\mathrm{RH}}{50}, \mathrm{P} 3$ represents the equation $\frac{V_{\mathrm{m}}}{70}$ and $\mathrm{P} 4$ represents the equation $\left(1+0.1 V_{\text {shear }}\right)^{-2}$. The results indicate that the pattern correlation coefficients are increased in the northern Indian (Fig. 12a), western Pacific (Fig. 12b), eastern Pacific (Fig. 12c) and northern Atlantic (Fig. 12d) oceans, which is favored by the reduction in the bias of the large-scale circulation patterns.

\section{Discussion}

\subsection{Impact of physical parameterization and air-sea coupling on tropical cyclones simulated in GCMs}

An RCP scheme has been used in both the high- and lowresolution versions of FGOALS-f3 (Bao and Li, 2020; He et al., 2019; Li et al., 2019). The RCP scheme calculates con- 

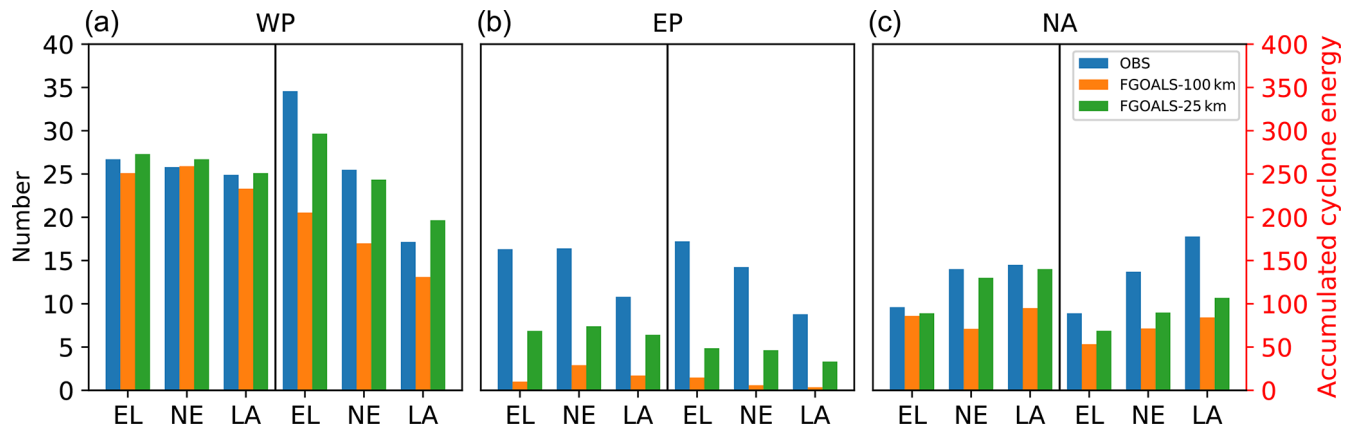

Figure 10. Bar chart showing the average number of tropical cyclones (left-hand panels) and ACE (right-hand panels) from El Niño (EL), neutral (NE) and La Niña (LA) years in the (a) western Pacific (WP), (b) eastern Pacific (EP) and (c) northern Atlantic (NA) oceans.

(a) $600 \mathrm{mb}-\mathrm{RH}-$ Model $(100 \mathrm{~km})$

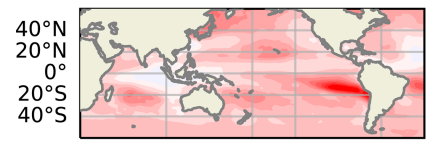

(c) $850 \mathrm{mb}$-Vorticity-Model $(100 \mathrm{~km})$

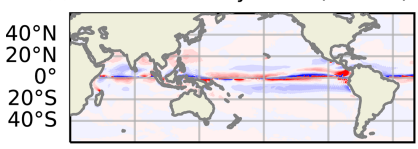

(e) WS-Model $(100 \mathrm{~km})$

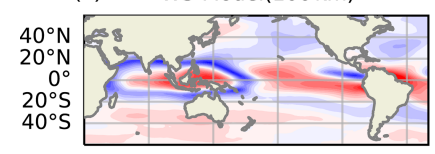

(g) PI-Model $(100 \mathrm{~km})$

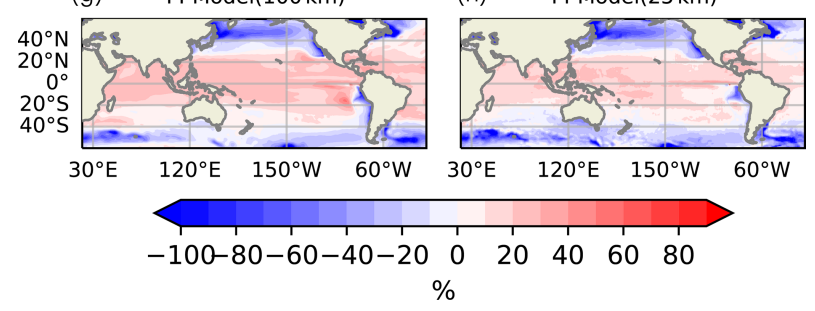

Figure 11. Biases in the large-scale environmental factors related to tropical cyclone activity between FGOALS-f3 and the observations. (a, b) Relative humidity biases at $600 \mathrm{hPa}$; (c, d) absolute vorticity biases at $850 \mathrm{hPa} ;(\mathbf{e}, \mathbf{f})$ wind shear biases between 200 and $850 \mathrm{hPa}$; and $(\mathbf{g}, \mathbf{h})$ potential intensity biases.

vective and stratiform precipitation at the grid scale, which has the advantage of both scale awareness and high computational efficiency. The parameterizations of physical processes in traditional GCMs are very sensitive to changes in resolution. In particular, convection and cloud processes are considered to be effectively resolved, which means that the assumptions and equations in low-resolution simulations are not suitable for high-resolution GCMs. As a result, the model convergence will be degraded as the resolution increases (Sakradzija et al., 2016). Simulated tropical cyclones are very sensitive to convection and cloud processes in GCMs (Zhao et al., 2012). The effective tuning of convection (Lim et al.,
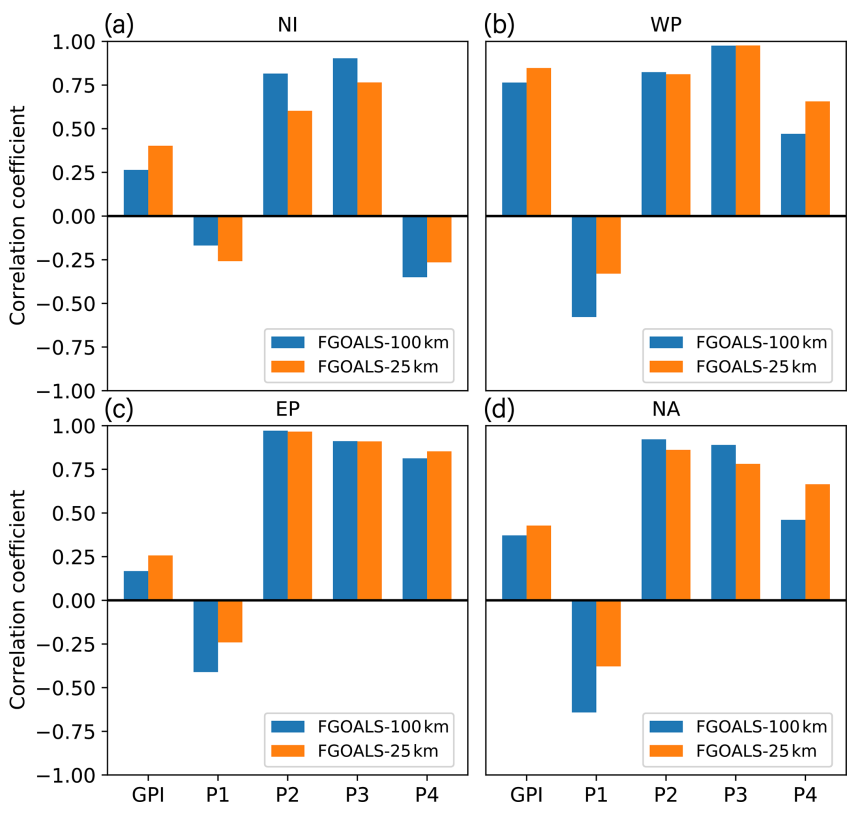

Figure 12. Pattern correlation of annual tropical cyclone GPI between the ERA-Interim dataset and the simulation of FGOALS-f3 at low (blue bars) and high (orange bars) horizontal resolutions in the (a) northern Indian, (b) western Pacific, (c) eastern Pacific and (d) northern Atlantic oceans. P1-P4 represent parts 1-4 of Eq. (2). P1 represents the equation $\mid 10^{5}$ vort850 $\left.\right|^{3 / 2}, \mathrm{P} 2$ represents the equation $\frac{\mathrm{RH}}{50}, \mathrm{P} 3$ represents the equation $\frac{V_{\mathrm{m}}}{70}$, and $\mathrm{P} 4$ represents the equation $\left(1+0.1 V_{\text {shear }}\right)^{-2}$.

2015; Murakami et al., 2012), boundary condition (Zhang et al., 2017) and microphysics (Chutia et al., 2019) parameterizations contributes to improvements in the intensity, number, track and structure of simulated tropical cyclone. Although a fixed parameterization scheme combined with a fine grid will clearly improve the simulation of tropical cyclone activity, the effect of resolution will be amplified. According to this study, GCMs with scale-aware parameterizations still slightly underestimate the intensity of tropical cyclones at $0.25^{\circ}$ resolution (Fig. 1). In addition, air-sea exchange and 
non-hydrostatic processes are both important in enhancing the intensity of tropical cyclones (Ma et al., 2017). Emanuel and Sobel (2013) found that the absence of air-sea coupling can lead to potentially large imbalances in the surface energy budget, which is not conducive to the development of tropical cyclones.

\subsection{Large-scale environmental factors from HighResMIP models}

Our results (Fig. 11) show a clear improvement in the largescale factors related to the generation and development of tropical cyclones when the horizontal resolution is increased from 100 to $25 \mathrm{~km}$ in FGOALS-f3. It is worth exploring whether these improved large-scale factors are common to all the GCMs participating in HighResMIP. The eight models participating in HighResMIP Tier 1 were selected (Table 6) to calculate the GPI. The results indicate that the GPI patterns in high-resolution models (Fig. 13b) are closer to the observations (Fig. 13a) than those in the standard-resolution models (Fig. 13c), which means that the large-scale factors related to tropical cyclones are improved when the horizontal resolution of the models is increased. However, the differences between the tracking algorithms - such as TRACK (Hodges et al., 2017), TSTORM (Zhao et al., 2009) and TempestExtremes (Ullrich and Zarzycki, 2017; Ullrich et al., 2021) - are also an important factor in the uncertainties in tropical cyclone simulations. Cross validation of the performance of tropical cyclone simulations with multiple tracking algorithms is necessary in future research (Roberts et al., 2020).

\section{Summary and conclusions}

The impacts of horizontal resolution on the simulation of tropical cyclones were studied with the latest version of FGOALS-f3, which participated in the CMIP6 HighResMIP (Haarsma et al., 2016). Li et al. (2019) evaluated the simulation performance of tropical cyclone activity in FAMIL2 (resolution about $100 \mathrm{~km}$ ), which is the atmospheric component of FGOALS-f3 (He et al., 2019) and put forward the idea that the simulated performance of tropical cyclones is improved with the increased horizontal resolution in FAMIL2. We examined these hypotheses and our main findings and conclusions are as follows.

1. There are improvements in the track and intensity of global tropical cyclones in the FGOALS-f3 simulations when the horizontal resolution is increased from 100 (FGOALS-f3-L) to $25 \mathrm{~km}$ (FGOALS-f3-H) and the negative biases in tropical cyclone genesis are improved in the eastern Pacific and northern Atlantic oceans. Quantitative comparisons between the track density of tropical cyclones between FGOALS-f3-L, FGOALS-f3-H and IBTrACS show that the negative biases in the trop-

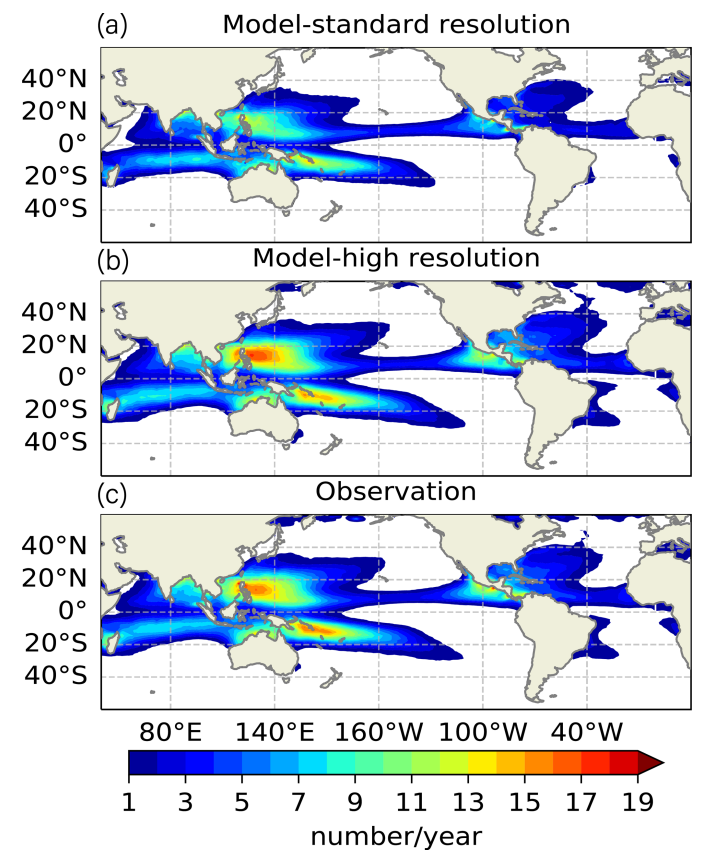

Figure 13. Global GPI pattern based on the multi-model mean of the (a) standard-resolution GCMs and (b) high-resolution GCMs and (c) ERA-Interim dataset.

ical cyclone track densities at low latitudes are alleviated. The surface wind speed of tropical cyclones is increased when the horizontal resolution is increased and this change in FGOALS-f3-H is closer to the observations. The improvement in the intensity of tropical cyclones in FGOALS-f3-H is easier to detect in the pressure-wind pairs of tropical cyclones. A wide spread of pressure-wind pairs is simulated in FGOALS-f3-H and the biases in the pressure-wind pairs are improved relative to the observations.

2. The global lifetimes of tropical cyclones in FGOALSf3-H are increased compared with the FGOALS-f3-L simulation, especially in the western Pacific, northern Atlantic, eastern Pacific and southern Pacific oceans. The increase in the intensity of tropical cyclones in FGOALS-f3-H contributes to the improvement in the lifetime of tropical cyclones. In the seasonal cycle of tropical cyclones, only $50 \%$ of tropical cyclones are simulated in the peak month, but this bias is improved in FGOALS-f3-H compared with the observations. Both FGOALS-f3-L and FGOALS-f3-H appear to replicate the timing of the seasonal cycle. The average ACE and number of tropical cyclones in FGOALS-f3-H are close to the observations. The correlation of the annual number of tropical cyclones and the annual ACE of tropical cyclones are both improved in the western Pacific, northern Atlantic, eastern Pacific, southern Pacific and 
Table 6. Information about the GCMs participating in HighResMIP.

\begin{tabular}{|c|c|c|c|}
\hline Institution & Model name & $\begin{array}{l}\text { Horizontal } \\
\text { resolution/nominal } \\
\text { resolution }(\mathrm{km})\end{array}$ & References \\
\hline Chinese Academy of Sciences & $\begin{array}{l}\text { FGOALS-f3-L } \\
\text { FGOALS-f3-H }\end{array}$ & $\begin{array}{l}\text { C96/100 } \\
\text { C384/25 }\end{array}$ & $\begin{array}{l}\text { Bao and } \mathrm{Li}(2020) \\
\text { He et al. (2019) } \\
\text { Li et al. (2019) }\end{array}$ \\
\hline Meteorological Research Institute & $\begin{array}{l}\text { MRI-AGCM3-2-H } \\
\text { MRI-AGCM3-2-S }\end{array}$ & $\begin{array}{l}\text { T319/50 } \\
\text { T959/25 }\end{array}$ & $\begin{array}{l}\text { Mizuta et al. (2012) } \\
\text { Murakami et al. (2012) }\end{array}$ \\
\hline Max Planck Institute for Meteorology & $\begin{array}{l}\text { MPI-ESM1-2-HR } \\
\text { MPI-ESM1-2-XR }\end{array}$ & $\begin{array}{l}\mathrm{T} 127 / 100 \\
\mathrm{~T} 255 / 50\end{array}$ & $\begin{array}{l}\text { Müller et al. (2018) } \\
\text { Gutjahr et al. (2019) }\end{array}$ \\
\hline Institute Pierre Simon Laplace & $\begin{array}{l}\text { IPSL-CM6A-LR } \\
\text { IPSL-CM6A-ATM-HR }\end{array}$ & $\begin{array}{l}\mathrm{N} 96 / 250 \\
\mathrm{~N} 256 / 50\end{array}$ & Boucher et al. (2020) \\
\hline $\begin{array}{l}\text { European Centre for Medium-Range } \\
\text { Weather Forecasts }\end{array}$ & $\begin{array}{l}\text { ECMWF-IFS-LR } \\
\text { ECMWF-IFS-HR }\end{array}$ & $\begin{array}{l}\text { Tco199/100 } \\
\text { Tco399/25 }\end{array}$ & Roberts et al. (2018) \\
\hline EC-Earth consortium & $\begin{array}{l}\text { EC-Earth3P } \\
\text { EC-Earth3-HR }\end{array}$ & $\begin{array}{l}\mathrm{T} 255 / 100 \\
\mathrm{~T} 511 / 50\end{array}$ & Haarsma et al. (2020) \\
\hline $\begin{array}{l}\text { Centre National de Recherches } \\
\text { Meteorologiques }\end{array}$ & $\begin{array}{l}\text { CNRM-CM6-1 } \\
\text { CNRM-CM6-1-HR }\end{array}$ & $\begin{array}{l}\mathrm{T} 127 / 250 \\
\mathrm{~T} 359 / 50\end{array}$ & Voldoire et al. (2019) \\
\hline Met Office Hadley Centre & $\begin{array}{l}\text { HadGEM3-GC31-LM } \\
\text { HadGEM3-GC31-HM }\end{array}$ & $\begin{array}{l}\mathrm{N} 96 / 250 \\
\mathrm{~N} 512 / 50\end{array}$ & Williams et al. (2018) \\
\hline
\end{tabular}

northern Indian oceans when the horizontal resolution is increased.

3. There is a significant improvement in the horizontal structure of tropical cyclones in FGOALS-f3 when the horizontal resolution is increased. The eyewall and the organized precipitation of tropical cyclones are apparent in the FGOALS-f3-H simulation and the main uncertainty is the position of extreme precipitation.

4. The possible reasons for the improvement in the simulated tropical cyclones are explained by the ENSO and large-scale environmental factors. FGOALS-f3 can reproduce the response between the ENSO and tropical cyclone activities, and the biases in the number of tropical cyclones and the ACE in FGOALS- $\mathrm{f} 3-\mathrm{H}$ are decreased. The large-scale factors and GPI biases between FGOALS-f3-L and FGOALS-f3-H are consistent with the biases in the simulated tropical cyclones, which means that the improvement in the large-scale environmental factors in FGOALS-f3 contributes to the simulation of tropical cyclones. This study shows that it is worth establishing a high-resolution coupled dynamic prediction system based on FGOALS-f3-H to improve the prediction skill of tropical cyclones on subseasonal to seasonal scales (Camp et al., 2019; Murakami et al., 2016). This dataset will be uploaded to the subseasonal to seasonal prediction project (Vitart and Robertson, 2018; Vitart et al., 2017). 


\section{Appendix A}

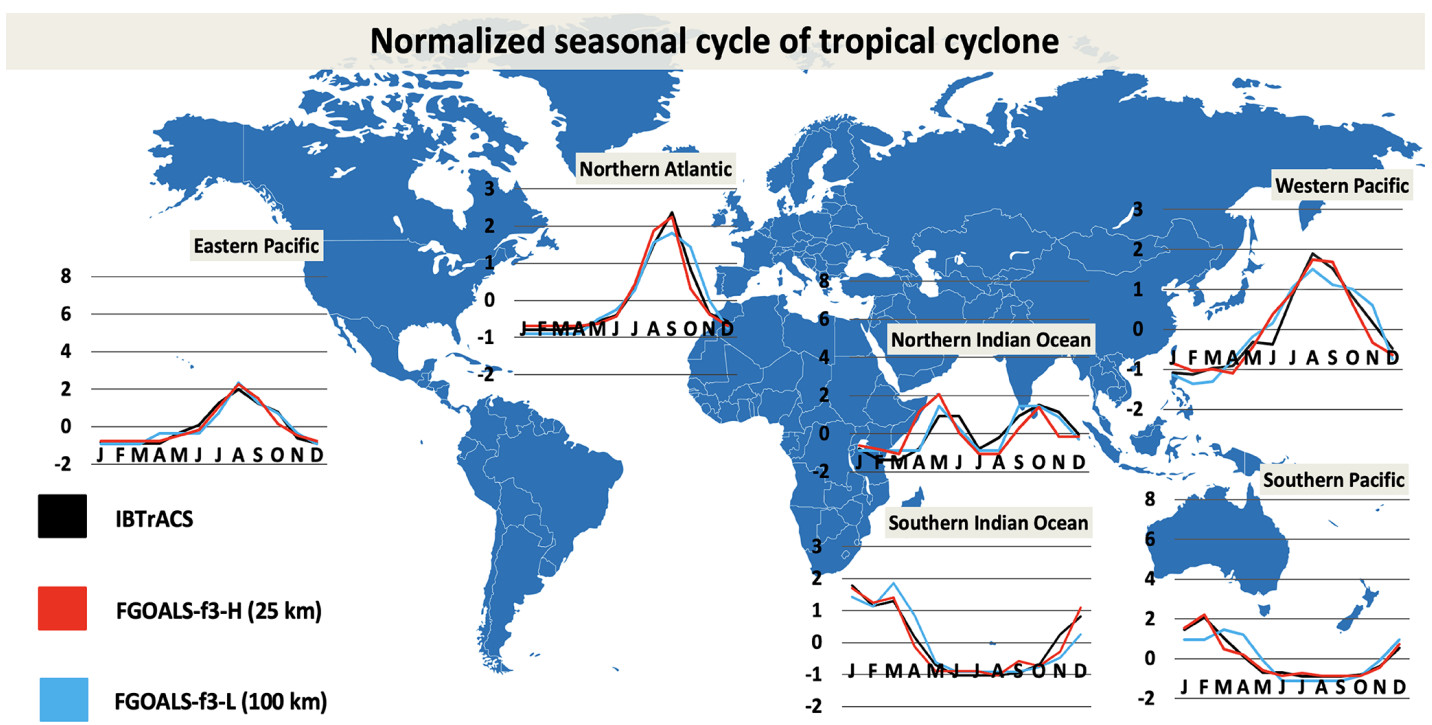

Figure A1. Seasonal cycle of tropical cyclones with zero-mean normalization in the western Pacific, southern Pacific, northern Indian, northern Atlantic, southern Indian and eastern Pacific oceans (units: number of cyclones) during the time period 1991-2014.

Code and data availability. The model output of the FGOALSf3 models for CMIP6 simulations used in this work has been uploaded to the Earth System Grid Federation (ESGF), and users can access these outputs freely. The DOI for CMIP6.HighResMIP.CAS.FGOALS-f3-H.highresSST-present is http://doi.org/10.22033/ESGF/CMIP6.3312 (Bao and $\mathrm{He}$, 2019a) and the DOI for CMIP6.HighResMIP.CAS.FGOALS-f3L.highresSST-present is http://doi.org/10.22033/ESGF/CMIP6. 12009 (Bao and He, 2019b). The other output of GCMs participating in HighResMIP (Table 6) is also distributed through the ESGF, and users can find it at https://esgf-node.llnl.gov/projects/cmip6/ (last access: 12 October 2021) after a simple registration (http://doi.org/10.22033/ESGF/CMIP6.10974, Mizuta et al., 2019a; http://doi.org/10.22033/ESGF/CMIP6.6942, Mizuta et al., 2019b; http://doi.org/10.22033/ESGF/CMIP6.6584, von Storch et al., 2017a; http://doi.org/10.22033/ESGF/CMIP6.10305, von Storch et al., 2017b; http://doi.org/10.22033/ESGF/CMIP6.13810, Boucher et al., 2019a; http://doi.org/10.22033/ESGF/CMIP6.5185, Boucher et al., 2019b; http://doi.org/10.22033/ESGF/CMIP6.4976, Roberts et al., 2017a; http://doi.org/10.22033/ESGF/CMIP6.4975, Roberts et al., 2017b; http://doi.org/10.22033/ESGF/CMIP6.4674, EC-Earth Consortium, 2017a; http://doi.org/10.22033/ ESGF/CMIP6.4675, EC-Earth Consortium, 2017b; http://doi.org/10.22033/ESGF/CMIP6.4035, Voldoire, 2019a; http://doi.org/10.22033/ESGF/CMIP6.4036, Voldoire, 2019b; http://doi.org/10.22033/ESGF/CMIP6.6027, Roberts, 2017a; http://doi.org/10.22033/ESGF/CMIP6.6024, Roberts, 2017b). The source code of the model can be found at http://doi.org/10.5281/zenodo.4588109 (Li, 2021). All the source code and data are available on request from the corresponding author, Qing Bao (baoqing@mail.iap.ac.cn).
Author contributions. QB led the development of CAS FGOALSf3 and all other co-authors contributed to it. JL participated in the development of CAS FGOALS- $f 3$ and evaluated the simulation performance of tropical cyclones in FGOALS-f3. YL, LW, JY, GW, $\mathrm{XWu}, \mathrm{BH}, \mathrm{XWa}, \mathrm{XZ}, \mathrm{YY}$ and ZS contributed to the writing of this paper.

Competing interests. The authors declare that they have no conflict of interest.

Disclaimer. Publisher's note: Copernicus Publications remains neutral with regard to jurisdictional claims in published maps and institutional affiliations.

Acknowledgements. The authors are grateful for the help from the handling topical editor, Paul Ullrich, and the two anonymous reviewers that made this research more meaningful.

Financial support. This research has been supported by the Strategic Priority Research Program of the Chinese Academy of Sciences (grant no. XDB40030205), the National Natural Science Foundation of China (grant no. 42005117) and the Key Special Project for Introduced Talents Team of Southern Marine Science and Engineering Guangdong Laboratory (Guangdong) (grant no. GML2019ZD0601). 
Review statement. This paper was edited by Paul Ullrich and reviewed by two anonymous referees.

\section{References}

Bacmeister, J. T., Wehner, M. F., Neale, R. B., Gettelman, A., Hannay, C., Lauritzen P. H., Caron, J. M., and Truesdale, J. E.: Exploratory high-resolution climate simulations using the Community Atmosphere Model (CAM), J. Climate, 27, 3073-3099, https://doi.org/10.1175/JCLI-D-13-00387.1, 2014.

Balaguru, K., Leung, L., R., Van Roekel, L., P., Golaz, J., C., Ullrich, P., A., Caldwell, P., M., Hagos, S., M., Harrop, B., E., and Mametjanov, A.: Characterizing tropical cyclones in the energy exascale earth system model Version 1, J. Adv. Model. Earth Sy., 12, e2019MS002024, https://doi.org/10.1029/2019MS002024, 2020.

Bao, Q. and He, B.: CAS FGOALS-f3-H model output prepared for CMIP6 HighResMIP highresSSTpresent, Earth System Grid Federation [data set], https://doi.org/10.22033/ESGF/CMIP6.3312, 2019a.

Bao, Q. and He, B.: CAS FGOALS-f3-L model output prepared for CMIP6 HighResMIP highresSSTpresent, Earth System Grid Federation [data set], https://doi.org/10.22033/ESGF/CMIP6.12009, 2019 b.

Bao, Q. and Li, J.: Progress in climate modeling of precipitation over the Tibetan Plateau, Natl. Sci. Rev., 7, 486-487, https://doi.org/10.1093/nsr/nwaa006, 2020.

Bao, Q., Wu, G., Liu, Y., Yang, J., Wang, Z., and Zhou, T.: An introduction to the coupled model FGOALS1. 1-s and its performance in East Asia, Adv. Atmos. Sci., 27, 1131-1142, https://doi.org/10.1007/s00376-010-9177-1, 2010.

Bao, Q., Lin, P., Zhou, T., Liu, Y., Yu, Y., Wu, G., He, B., He, J., Li, L., and Li, J.: The flexible global ocean-atmosphere-land system model, spectral version 2: FGOALS-s2, Adv. Atmos. Sci., 30, 561-576, https://doi.org/10.1007/s00376-012-2113-9, 2013.

Bao, Q., Wu, X., Li, J., Wang, L., He, B., Wang, X., Liu, Y., and Wu, G.: Outlook for El Niño and the Indian Ocean Dipole in autumn-winter 2018-2019, Chinese Sci. Bull., 64, 73-78, 2018.

Bell, G. and Chelliah, M.: The 1999 North Atlantic and eastern North Pacific hurricane season [in "Climate Assessment for 1999"], B. Am. Meteorol. Soc., 81, S19-S22, https://doi.org/10.1175/1520-0477-80.5s.S1, 2000.

Bell, R., Hodges, K., Vidale, P. L., Strachan, J., and Roberts, M.: Simulation of the global ENSO-tropical cyclone teleconnection by a high-resolution coupled general circulation model, J. Climate, 27, 6404-6422, https://doi.org/10.1175/JCLI-D-13$00559.1,2014$.

Benfield, A.: Global economic losses. Weather, climate \& catastrophe insight: 2017 annual report, Aon Benfield UCL Hazard Research Centre Rep., 2-5, available at: http://thoughtleadership.aonbenfield.com/Documents/ 20180124-abif-annual-report-weather-climate-2017.pdfTS47 (last access: 8 October 2021), 2018.

Bengtsson, L., Böttger, H., and Kanamitsu, M.: Simulation of hurricane-type vortices in a general circulation model, Tellus, 34, 440-457, https://doi.org/10.1111/j.21533490.1982.tb01833.x, 1982.
Boucher, O., Denvil, S., Levavasseur, G., Cozic, A., Caubel, A., Foujols, M. A., Meurdesoif, Y., and Ghattas, J.: IPSL IPSLCM6A-LR model output prepared for CMIP6 HighResMIP highresSST-present, Earth System Grid Federation [data set], https://doi.org/10.22033/ESGF/CMIP6.13810, 2019a.

Boucher, O., Denvil, S., Levavasseur, G., Cozic, A., Caubel, A., Foujols, M. A., Meurdesoif, Y., and Ghattas, J.: IPSL IPSL-CM6A-ATM-HR model output prepared for CMIP6 HighResMIP highresSST-present, Earth System Grid Federation [data set], https://doi.org/10.22033/ESGF/CMIP6.5185, 2019b.

Boucher, O., Servonnat, J., Albright, A. L., Aumont, O., Balkanski, Y., Bastrikov, V., Bekki, S., Bonnet, R., Bony, S., Bopp, L., Braconnot, P., Brockmann, P., Cadule, P., Caubel, A., Cheruy, F., Codron, F., Cozic, A., Cugnet, D., D’Andrea, F., Davini, P., de Lavergne, C., Denvil, S., Deshayes, J., Devilliers, M., Ducharne, A., Dufresne, J.-L., Dupont, E., Éthé, C., Fairhead, L., Falletti, L., Flavoni, S., Foujols, M.- A., Gardoll, S., Gastineau, G., Ghattas, J., Grandpeix, J.-Y., Guenet, B., Guez, L.E., Guilyardi, E., Guimberteau, M., Hauglustaine, D., Hourdin, F., Idelkadi, A., Joussaume, S., Kageyama, M., Khodri, M., Krinner, G., Lebas, N., Levavasseur, G., Lévy, C., Li, L., Lott, F., Lurton, T., Luyssaert, S., Madec, G., Madeleine, J.-B., Maignan, F., Marchand, M., Marti, O., Mellul, L., Meurdesoif, Y., Mignot, J., Musat, I., Ottlé, C., Peylin, P., Planton, Y., Polcher, J., Rio, C., Rochetin, N., Rousset, C., Sepulchre, P., Sima, A., Swingedouw, D., Thiéblemont, R., Traore, A. K., Vancoppenolle, M., Vial, J., Vialard, J., Viovy, N., and Vuichard, N. : Presentation and evaluation of the IPSL-CM6A-LR climate model, J. Adv. Model. Earth Sy., 2020, 12, e2019MS002010, https://doi.org/10.1029/2019MS002010, 2020.

Camargo, S. J.: Global and regional aspects of tropical cyclone activity in the CMIP5 models, J. Climate, 26, 9880-9902, https://doi.org/10.1175/JCLI-D-12-00549.1, 2013.

Camargo, S. J. and Sobel, A. H.: Western North Pacific tropical cyclone intensity and ENSO, J. Climate, 18, 2996-3006, https://doi.org/10.1175/JCLI3457.1, 2005.

Camargo, S. J. and Wing, A. A.: Tropical cyclones in climate models, Wiley Interdiscip. Rev. Clim. Change, 7, 211-237, https://doi.org/10.1002/wcc.373, 2016.

Camargo, S. J., Emanuel, K. A., and Sobel, A. H.: Use of a genesis potential index to diagnose ENSO effects on tropical cyclone genesis, J. Climate, 20, 4819-4834, https://doi.org/10.1175/JCLI4282.1, 2007.

Camargo, S. J., Robertson, A. W., Barnston, A. G., and Ghil, M.: Clustering of eastern North Pacific tropical cyclone tracks: ENSO and MJO effects, Geochem. Geophy. Geosy., 9, 1-23, https://doi.org/10.1029/2007GC001861, 2008.

Camargo, S. J., Wheeler, M. C., and Sobel, A. H.: Diagnosis of the MJO modulation of tropical cyclogenesis using an empirical index, J. Atmos. Sci., 66, 3061-3074, https://doi.org/10.1175/2009JAS3101.1, 2009.

Camp, J., Roberts, M. J., Comer, R. E., Wu, P., MacLachlan, C., Bett, P. E., Golding, N., Toumi, R., and Chan, J. C.: The western Pacific subtropical high and tropical cyclone landfall: Seasonal forecasts using the Met Office GloSea5 system, Q. J. Roy. Meteor. Soc., 145, 105-116, https://doi.org/10.1002/qj.3407, 2019.

Chen, J.-H. and Lin, S.-J.: Seasonal predictions of tropical cyclones using a $25-\mathrm{km}$-resolution general circulation model, J. Climate, 26, 380-398, https://doi.org/10.1175/JCLI-D-12-00061.1, 2013. 
Chen, S., Knaff, J. A., and Marks, F. D.: Effects of vertical wind shear and storm motion on tropical cyclone rainfall asymmetries deduced from TRMM, Mon. Weather Rev., 13, 3190-3208, https://doi.org/10.1175/MWR3245.1, 2006.

Chutia, L., Pathak, B., Parottil, A., and Bhuyan, P. K.: Impact of microphysics parameterizations and horizontal resolutions on simulation of "MORA" tropical cyclone over Bay of Bengal using Numerical Weather Prediction Model, Meteorol. Atmos. Phys., 131, 1483-1495, https://doi.org/10.1007/s00703018-0651-0, 2019.

Clough, S., Shephard, M., Mlawer, E., Delamere, J., Iacono, M., Cady-Pereira, K., Boukabara, S., and Brown, P.: Atmospheric radiative transfer modeling: a summary of the AER codes, J. Quant. Spectrosc. RA., 91, 233-244, https://doi.org/10.1016/j.jqsrt.2004.05.058, 2005.

Craig, A. P., Vertenstein, M., and Jacob, R.: A new flexible coupler for earth system modeling developed for CCSM4 and CESM1, Int. J. High Perform. C., 26, 31-42, https://doi.org/10.1177/1094342011428141, 2012.

Dee, D. P., Uppala, S., Simmons, A., Berrisford, P., Poli, P., Kobayashi, S., Andrae, U., Balmaseda, M., Balsamo, G., and Bauer, d. P.: The ERA-Interim reanalysis: Configuration and performance of the data assimilation system, Q. J. Roy. Meteor. Soc., 137, 553-597, https://doi.org/10.1002/qj.828, 2011.

Delworth, T. L., Cooke, W. F., Adcroft, A., Bushuk, M., Chen, J. H., Dunne, K. A., Ginoux, P., Gudgel, R., Hallberg, R. W., and Harris, L.: SPEAR: The Next Generation GFDL Modeling System for Seasonal to Multidecadal Prediction and Projection, J. Adv. Model. Earth Sy., 12, e2019MS001895, https://doi.org/10.1029/2019MS001895, 2020

EC-Earth Consortium: EC-Earth-Consortium EC-Earth3P model output prepared for CMIP6 HighResMIP highresSSTpresent, Earth System Grid Federation [data set], https://doi.org/10.22033/ESGF/CMIP6.4674, 2017a.

EC-Earth Consortium: EC-Earth-Consortium EC-Earth3PHR model output prepared for CMIP6 HighResMIP highresSST-present, Earth System Grid Federation [data set], https://doi.org/10.22033/ESGF/CMIP6.4675, 2017b.

Emanuel, K.: Sensitivity of tropical cyclones to surface exchange coefficients and a revised steadystate model incorporating eye dynamics, J. Atmos. Sci., 52, 3969-3976, https://doi.org/10.1175/15200469(1995)052<3969:SOTCTS>2.0.CO;2, 1995.

Emanuel, K.: Downscaling CMIP5 climate models shows increased tropical cyclone activity over the $21 \mathrm{st}$ century, P. Natl. Acad. Sci. USA, 110, 12219-12224, https://doi.org/10.1073/pnas.1301293110, 2013.

Emanuel, K.: Assessing the present and future probability of Hurricane Harvey's rainfall, P. Natl. Acad. Sci. USA, 114, 1268112684, https://doi.org/10.1073/pnas.1716222114, 2017.

Emanuel, K. and Sobel, A.: Response of tropical sea surface temperature, precipitation, and tropical cyclone-related variables to changes in global and local forcing, J. Adv. Model. Earth Sy., 5, 447-458, https://doi.org/10.1002/jame.20032, 2013.

Emanuel, K., DesAutels, C., Holloway, C., and Korty, R.: Environmental control of tropical cyclone intensity, J. Atmos. Sci., 61, 843-858, https://doi.org/10.1175/15200469(2004)061<0843:ECOTCI>2.0.CO;2, 2004.
Eyring, V., Bony, S., Meehl, G. A., Senior, C. A., Stevens, B., Stouffer, R. J., and Taylor, K. E.: Overview of the Coupled Model Intercomparison Project Phase 6 (CMIP6) experimental design and organization, Geosci. Model Dev., 9, 1937-1958, https://doi.org/10.5194/gmd-9-1937-2016, 2016.

Gray, W. M.: Global view of the origin of tropical disturbances and storm, Mon. Weather Rev., 96, 669-700, https://doi.org/10.1175/15200493(1968)096<0669:GVOTOO>2.0.CO;2, 1968.

Gray, W. M.: Atlantic seasonal hurricane frequency. Part I: El Niño and $30 \mathrm{mb}$ quasi-biennial oscillation influences, Mon. Weather Rev., 112.9, 1649-1668, https://doi.org/10.1175/15200493(1984)112<1649:ASHFPI>2.0.CO;2, 1984.

Gutjahr, O., Putrasahan, D., Lohmann, K., Jungclaus, J. H., von Storch, J.-S., Brüggemann, N., Haak, H., and Stössel, A.: Max Planck Institute Earth System Model (MPIESM1.2) for the High-Resolution Model Intercomparison Project (HighResMIP), Geosci. Model Dev., 12, 3241-3281, https://doi.org/10.5194/gmd-12-3241-2019, 2019.

Haarsma, R., Acosta, M., Bakhshi, R., Bretonnière, P.-A., Caron, L.-P., Castrillo, M., Corti, S., Davini, P., Exarchou, E., Fabiano, F., Fladrich, U., Fuentes Franco, R., García-Serrano, J., von Hardenberg, J., Koenigk, T., Levine, X., Meccia, V. L., van Noije, T., van den Oord, G., Palmeiro, F. M., Rodrigo, M., RuprichRobert, Y., Le Sager, P., Tourigny, E., Wang, S., van Weele, M., and Wyser, K.: HighResMIP versions of EC-Earth: EC-Earth3P and EC-Earth3P-HR - description, model computational performance and basic validation, Geosci. Model Dev., 13, 3507-3527, https://doi.org/10.5194/gmd-13-3507-2020, 2020.

Haarsma, R. J., Mitchell, J. F., and Senior, C.: Tropical disturbances in a GCM, Clim. Dynam., 8, 247-257, https://doi.org/10.1007/BF00198619, 1993.

Haarsma, R. J., Roberts, M. J., Vidale, P. L., Senior, C. A., Bellucci, A., Bao, Q., Chang, P., Corti, S., Fučkar, N. S., Guemas, V., von Hardenberg, J., Hazeleger, W., Kodama, C., Koenigk, T., Leung, L. R., Lu, J., Luo, J.-J., Mao, J., Mizielinski, M. S., Mizuta, R., Nobre, P., Satoh, M., Scoccimarro, E., Semmler, T., Small, J., and von Storch, J.-S.: High Resolution Model Intercomparison Project (HighResMIP v1.0) for CMIP6, Geosci. Model Dev., 9, 4185-4208, https://doi.org/10.5194/gmd-9-4185-2016, 2016.

Hall, J. D., Matthews, A. J., and Karoly, D. J.: The modulation of tropical cyclone activity in the Australian region by the Madden-Julian oscillation, Mon. Weather Rev., 129, 2970-2982, https://doi.org/10.1175/15200493(2001)129<2970:TMOTCA>2.0.CO;2, 2001.

He, B., Bao, Q., Wang, X., Zhou, L., Wu, X., Liu, Y., Wu, G., Chen, K., He, S., Hu, W., Li, J., Li, J., Nian, G., Wang, L., Yang, J., Zhang, M., and Zhang, X.: CAS FGOALS-f3-L model datasets for CMIP6 historical atmospheric model Intercomparison project simulation, Adv. Atmos. Sci., 36, 771-778, https://doi.org/10.1007/s00376-019-9027-8, 2019..

He, B., Liu, Y., Wu, G., Bao, Q., Zhou, T., Wu, X., Wang, L., Li, J., Wang, X., and Li, J.: CAS FGOALS-f3-L Model Datasets for CMIP6 GMMIP Tier-1 and Tier-3 Experiments, Adv. Atmos. Sci., 37, 18-28, https://doi.org/10.1007/s00376-019-9085y, 2020.

Hodges, K., Cobb, A., and Vidale, P. L.: How well are tropical cyclones represented in reanalysis datasets?, J. Climate, 30, 52435264, https://doi.org/10.1175/JCLI-D-16-0557.1, 2017. 
Hou, A. Y., Kakar, R. K., Neeck, S., Azarbarzin, A. A., Kummerow, C. D., Kojima, M., Oki, R., Nakamura, K., and Iguchi, T.: The global precipitation measurement mission, B. Am. Meteorol. Soc., 95, 701-722, https://doi.org/10.1175/BAMS-D-1300164.1, 2014.

Hunke, E. C. and Lipscomb, W. H.: CICE: The Los Alamos Sea Ice Model, Documentation and Software User's Manual, Version 4.1, Tech. Rep. LA-CC-06-012, Los Alamos National Laboratory, Los Alamos, New Mexico, available at: http://oceans11. lanl.gov/trac/CICE (last access: 8 October 2021), 2010.

Hunke, E. C., Lipscomb, W. H., Turner, A., Jeffery, N., and Elliott, S.: CICE: the Los Alamos sea ice model documentation and software user's manual, T-3 Fluid Dynamics Group, Los Alamos National Laboratory, Los Alamos, NM, 87545, 2008.

Klotzbach, P. J.: The Madden-Julian oscillation's impacts on worldwide tropical cyclone activity, J. Climate, 27, 2317-2330, https://doi.org/10.1175/JCLI-D-13-00483.1, 2014.

Kim, D., Ho, C. H., Park, D. S., Chan, J. C. L., and Jung, Y.: The Relationship between Tropical Cyclone Rainfall Area and Environmental Conditions over the Subtropical Oceans, J. Climate, 31, 4605-4616, https://doi.org/10.1175/JCLI-D-17-0712.1, 2018.

Kim, H., M., Webster, P. J., and Curry, J. A.: Modulation of North Pacific tropical cyclone activity by three phases of ENSO, J. Climate, 24, 1839-1849, https://doi.org/10.1175/2010JCLI3939.1, 2011.

Kim, H. S., Vecchi, G. A., Knutson, T. R., Anderson, W. G., Delworth, T. L., Rosati, A., Zeng, F., and Zhao, M.: Tropical cyclone simulation and response to $\mathrm{CO}_{2}$ doubling in the GFDL CM2.5 high-resolution coupled climate model, J. Climate, 27, 8034-8054, https://doi.org/10.1175/JCLI-D-13-00475.1, 2014.

Knapp, K. R., Kruk, M. C., Levinson, D. H., Diamond, H. J., and Neumann, C. J.: The international best track archive for climate stewardship (IBTrACS) unifying tropical cyclone data, B. Am. Meteorol. Soc., 91, 363-376, https://doi.org/10.1175/2009BAMS2755.1, 2010.

Knutson, T., Camargo, S. J., Chan, J. C., Emanuel, K., Ho, C.-H., Kossin, J., Mohapatra, M., Satoh, M., Sugi, M., and Walsh, K.: Tropical Cyclones and Climate Change Assessment: Part I: Detection and Attribution, B. Am. Meteorol. Soc., 100, 1987-2007, https://doi.org/10.1175/BAMS-D-18-0189.1, 2019.

Knutson, T., Camargo, S. J., Chan, J. C., Emanuel, K., Ho, C.H., Kossin, J., Mohapatra, M., Satoh, M., Sugi, M., and Walsh, K.: Tropical cyclones and climate change assessment: Part II: Projected response to anthropogenic warming, B. Am. Meteorol. Soc., 101, E303-E322, https://doi.org/10.1175/BAMS-D18-0194.1, 2020.

Knutson, T. R., Manabe, S., and Gu, D.: Simulated ENSO in a global coupled ocean-atmosphere model: Multidecadal amplitude modulation and $\mathrm{CO}_{2}$ sensitivity, J. Climate, 10, 138-161, https://doi.org/10.1175/15200442(1997)010<0138:SEIAGC>2.0.CO;2, 1997.

Knutson, T. R., Sirutis, J. J., Garner, S. T., Held, I. M., and Tuleya, R. E.: Simulation of the recent multidecadal increase of Atlantic hurricane activity using an 18-km-grid regional model, B. Am. Meteorol. Soc., 88, 1549-1565, https://doi.org/10.1175/BAMS88-10-1549, 2007.

Krishnamurthy, L., Vecchi, G. A., Msadek, R., Murakami, H., Wittenberg, A., and Zeng, F.: Impact of strong ENSO on regional tropical cyclone activity in a high-resolution climate model in the
North Pacific and North Atlantic Oceans, J. Climate, 29, 23752394, https://doi.org/10.1175/JCLI-D-15-0468.1, 2016.

Krishnamurti, T. N. and Oosterhof, D.: Prediction of the life cycle of a supertyphoon with a high-resolution global model, B. Am. Meteorol. Soc., 70, 1218-1230, https://doi.org/10.1175/15200477(1989)070<1218:POTLCO>2.0.CO;2, 1989.

Larson, S. and Kirtman, B.: The Pacific Meridional Mode as a trigger for ENSO in a high-resolution coupled model, B. Am. Meteorol. Soc. B. Am. Meteorol. Soc., 40, 3189-3194, https://doi.org/10.1002/grl.50571, 2013.

Lawrence, D. M., Oleson, K. W., Flanner, M. G., Thornton, P. E., Swenson, S. C., Lawrence, P. J., Zeng, X., Yang, Z. L., Levis, S., and Sakaguchi, K.: Parameterization improvements and functional and structural advances in version 4 of the Community Land Model, J. Adv. Model. Earth Sy., 3, 1-27, https://doi.org/10.1029/2011MS00045, 2011.

Li, H. and Sriver, R. L.: Tropical cyclone activity in the highresolution community earth system model and the impact of ocean coupling, J. Adv. Model. Earth Sy., 10, 165-186, https://doi.org/10.1002/2017MS001199, 2018.

Li, J.: The code of FGOALS-f3 (V1.0), Zenodo [code], https://doi.org/10.5281/zenodo.4588109, 2021.

Li, J., Bao, Q., Liu, Y., and Wu, G.: Evaluation of the computational performance of the finite-volume atmospheric model of the IAP/LASG (FAMIL) on a high-performance computer, Atmos. Oceanic Sci. Lett., 10, 329-336, https://doi.org/10.1080/16742834.2017.1331111, 2017.

Li, J., Bao, Q., Liu, Y., Wu, G., Wang, L., He, B., Wang, X., and Li, J.: Evaluation of FAMIL2 in simulating the climatology and seasonal-to-interannual variability of tropical cyclone characteristics, J. Adv. Model. Earth Sy., 11, 1117-1136, https://doi.org/10.1029/2018MS001506, 2019.

Liebmann, B., Hendon, H. H., and Glick, J. D.: The relationship between tropical cyclones of the western Pacific and Indian Oceans and the Madden-Julian oscillation, J. Meteorol. Soc. Jpn., 72, 401-412, https://doi.org/10.2151/jmsj1965.72.3_401, 1994.

Lim, Y. K., Schubert, S. D., Reale, O., Lee, M, I., Molod, A. M., and Suarez, M. J.: Sensitivity of tropical cyclones to parameterized convection in the NASA GEOS-5 mode, J. Climate, 28, 551573, https://doi.org/10.1175/JCLI-D-14-00104.1, 2015.

Lin, S.-J.: A "vertically Lagrangian" finite-volume dynamical core for global models, Mon. Weather Rev., 132, 2293-2307, https://doi.org/10.1175/15200493(2004)132<2293:AVLFDC>2.0.CO;2, 2004.

Liu, H., Lin, P., Yu, Y., and Zhang, X.: The baseline evaluation of LASG/IAP climate system ocean model (LICOM) version 2, Acta Meteorol. Sin., 26, 318-329, https://doi.org/10.1007/s13351-012-0305-y, 2012.

Ma, Y., Davidson, N. E., Xiao, Y., and Bao, J. W.: Revised parameterization of air-sea exchanges in high winds for operational numerical prediction: Impact on tropical cyclone track, intensity, and rapid intensification, Weather Forecast., 32, 821-848, https://doi.org/10.1175/WAF-D-15-0109.1, 2017.

Manabe, S. and Broccoli, A.: Mountains and arid climates of middle latitudes, Science, 247, 192-195, https://doi.org/10.1126/science.247.4939.192, 1990.

Manabe, S., Holloway Jr., J. L., and Stone, H. M.: Tropical circulation in a time-integration of a global model of the atmosphere, 
J. Atmos. Sci., 27, 580-613, https://doi.org/10.1175/15200469(1970)027<0580:TCIATI>2.0.CO;2, 1970.

Manganello, J. V., Hodges, K. I., Kinter III, J. L., Cash, B. A., Marx, L., Jung, T., Achuthavarier, D., Adams, J. M., Altshuler, E. L., and Huang, B.: Tropical cyclone climatology in a 10-km global atmospheric GCM: toward weather-resolving climate modeling, J. Climate, 25, 3867-3893, https://doi.org/10.1175/JCLI-D-1100346.1, 2012.

Manganello, J. V., Hodges, K. I., Cash, B. A., Kinter III, J. L., Altshuler, E. L., Fennessy, M. J., Vitart, F., Molteni, F., and Towers, P.: Seasonal forecasts of tropical cyclone activity in a high-atmospheric-resolution coupled prediction system, J. Climate, 29, 1179-1200, https://doi.org/10.1175/JCLI-D-150531.1, 2016.

Masson, S., Terray, P., Madec, G., Luo, J.-J., Yamagata, T., and Takahashi, K.: Impact of intra-daily SST variability on ENSO characteristics in a coupled model, Clim. Dynam., 39, 681-707, https://doi.org/10.1007/s00382-011-1247-2, 2012

Matsuura, T., Yumoto, M., Iizuka, S., and Kawamura, R.: Typhoon and ENSO simulation using a high-resolution coupled GCM, Geophys. Res. Lett., 26, 1755-1758, https://doi.org/10.1029/1999GL900329, 1999.

Meehl, G. A., Shields, C., Arblaster, J. M., Annamalai, H., and Neale, R.: Intraseasonal, seasonal, and interannual characteristics of regional monsoon simulations in CESM2, J. Adv. Model. Earth Sy., 12, e2019MS001962, https://doi.org/10.1029/2019MS001962, 2020

Mendelsohn, R., Emanuel, K., Chonabayashi, S., and Bakkensen, L.: The impact of climate change on global tropical cyclone damage, Nat. Clim. Change, 2, 205-209, https://doi.org/10.1038/nclimate1357, 2012.

Mizuta, R., Yoshimura, H., Murakami, H., Matsueda, M., Endo, H., Ose, T., Kamiguchi, K., Hosaka, M., Sugi, M., Yukimoto, S., Kusunoki, S., and Kitoh, A.: Climate simulations using MRIAGCM3. 2 with 20-km grid, J. Meteorol. Soc. Jpn., 90, 233-258, https://doi.org/10.2151/jmsj.2012-A12, 2012.

Mizuta, R., Yoshimura, H., Ose, T., Hosaka, M., and Yukimoto, S.: MRI MRI-AGCM3-2-H model output prepared for CMIP6 HighResMIP highresSST-present, Earth System Grid Federation [data set], https://doi.org/10.22033/ESGF/CMIP6.10974, 2019a.

Mizuta, R., Yoshimura, H., Ose, T., Hosaka, M., and Yukimoto, S.: MRI MRI-AGCM3-2-S model output prepared for CMIP6 HighResMIP highresSST-present, Earth System Grid Federation [data set], https://doi.org/10.22033/ESGF/CMIP6.6942, 2019b.

Müller, W. A., Jungclaus, J. H., Mauritsen, T., Mauritsen, T., Baehr, J., Bittner, M., Budich, R., Bunzel, F., Esch, M., Ghosh, R., Haak, H., Ilyina, T., Kleine, T., Kornblueh, L., Li, H., Modali, K., Notz, D., Pohlmann, H., Roeckner, E., Stemmler, I., Tian, F., and Marotzke, J.: A Higher-resolution Version of the Max Planck Institute Earth System Model (MPIESM1. 2-HR), J. Adv. Model. Earth Sy., 10, 1383-1413, https://doi.org/10.1029/2017MS001217, 2018

Murakami, H., Wang, Y., Yoshimura, H., Mizuta, R., Sugi, M., Shindo, E., Adachi, Y., Yukimoto, S., Hosaka, M., and Kusunoki, S.: Future changes in tropical cyclone activity projected by the new high-resolution MRI-AGCM, J. Climate, 25, 3237-3260, https://doi.org/10.1007/s00382-012-1407-z, 2012.

Murakami, H., Sugi, M., and Kitoh, A.: Future changes in tropical cyclone activity in the North Indian Ocean projected by high-resolution MRI-AGCMs, Clim. Dynam., 40, 1949-1968, https://doi.org/10.1007/s00382-012-1407-z, 2013.

Murakami, H., Vecchi, G. A., Villarini, G., Delworth, T. L., Gudgel, R., Underwood, S., Yang, X., Zhang, W., and Lin, S.-J.: Seasonal forecasts of major hurricanes and landfalling tropical cyclones using a high-resolution GFDL coupled climate model, J. Climate, 29, 7977-7989, https://doi.org/10.1175/JCLI-D-160233.1, 2016.

Oleson, K. W., Lawrence, D. M., Bonan, G. B., Flanner, M. G., Kluzek, E., Lawrence, P. J., Levis, S., Swenson, S. C., Thornton, P. E., Dai, A., Decker, M., Dickinson, R., Feddema, J., Heald, C. L., Hoffman, F., Lamarque, J.-F., Mahowald, N., Niu, G.-Y., Qian, T., Randerson, J., Running, S., Sakaguchi, K., Slater, A., Stockli, R., Wang, A., Yang, Z.-L., Zeng, X., and Zeng, X.: Technical Description of version 4.0 of the Community Land Model (CLM), Tech. Rep. NCAR/TN-478+STR, National Center for Atmospheric Research, Boulder, Colorado, USA, 2010.

Oouchi, K., Yoshimura, J., Yoshimura, H., Mizuta, R., Kusunoki, S., and Noda, A.: Tropical cyclone climatology in a global-warming climate as simulated in a $20 \mathrm{~km}$-mesh global atmospheric model: Frequency and wind intensity analyses, J. Meteorol. Soc. Jpn., 84, 259-276, https://doi.org/10.2151/jmsj.84.259, 2006.

Palmer, T., Shutts, G., and Swinbank, R.: Alleviation of a systematic westerly bias in general circulation and numerical weather prediction models through an orographic gravity wave drag parametrization, Q. J. Roy. Meteor. Soc., 112, 1001-1039, https://doi.org/10.1002/qj.49711247406, 1986.

Park, S. and Bretherton, C. S.: The University of Washington shallow convection and moist turbulence schemes and their impact on climate simulations with the Community Atmosphere Model, J. Climate, 22, 3449-3469, https://doi.org/10.1175/2008JCLI2557.1, 2009.

Philander, S., Pacanowski, R., Lau, N.-C., and Nath, M.: Simulation of ENSO with a global atmospheric GCM coupled to a high-resolution, tropical Pacific Ocean GCM, J. Climate, 5, 308-329, https://doi.org/10.1175/15200442(1992)005<0308:SOEWAG>2.0.CO;2, 1992.

Putman, W. M. and Lin, S.-J.: Finite-volume transport on various cubed-sphere grids, J. Comput. Phys., 227, 55-78, https://doi.org/10.1016/j.jcp.2007.07.022, 2007.

Roberts, C. D., Senan, R., Molteni, F., Boussetta, S., and Keeley, S.: ECMWF ECMWF-IFS-LR model output prepared for CMIP6 HighResMIP highresSST-present, Earth System Grid Federation [data set], https://doi.org/10.22033/ESGF/CMIP6.4976, 2017a.

Roberts, C. D., Senan, R., Molteni, F., Boussetta, S., and Keeley, S.: ECMWF ECMWF-IFS-HR model output prepared for CMIP6 HighResMIP highresSST-present, Earth System Grid Federation [data set], https://doi.org/10.22033/ESGF/CMIP6.4975, 2017b.

Roberts, C. D., Senan, R., Molteni, F., Boussetta, S., Mayer, M., and Keeley, S. P. E.: Climate model configurations of the ECMWF Integrated Forecasting System (ECMWF-IFS cycle 43r1) for HighResMIP, Geosci. Model Dev., 11, 3681-3712, https://doi.org/10.5194/gmd-11-3681-2018, 2018.

Roberts, M.: MOHC HadGEM3-GC31-LM model output prepared for CMIP6 HighResMIP highresSSTpresent, Earth System Grid Federation [data set], https://doi.org/10.22033/ESGF/CMIP6.6027, 2017a.

Roberts, M.: MOHC HadGEM3-GC31-HM model output prepared for CMIP6 HighResMIP highresSST- 
present, Earth System Grid Federation [data set], https://doi.org/10.22033/ESGF/CMIP6.6024, 2017b.

Roberts, M. J., Camp, J., Seddon, J., Vidale, P. L., Hodges, K., Vanniere, B., Mecking, J., Haarsma, R., Bellucci, A., and Scoccimarro, E.: Impact of Model Resolution on Tropical Cyclone Simulation Using the HighResMIPPRIMAVERA Multimodel Ensemble, J. Climate, 33, 25572583, https://doi.org/10.1175/JCLI-D-19-0639.1, 2020.

Sakradzija, M., Seifert, A., and Dipankar, A.: A stochastic scaleaware parameterization of shallow cumulus convection across the convective gray zone, J. Adv. Model. Earth Sy., 8, 786-812, https://doi.org/10.1002/2016MS000634, 2016.

Schneider, E. K., Kirtman, B. P., DeWitt, D. G., Rosati, A., Ji, L., and Tribbia, J. J.: Retrospective ENSO forecasts: sensitivity to atmospheric model and ocean resolution, Mon. Weather Rev., 131, 3038-3060, https://doi.org/10.1175/15200493(2003)131<3038:REFSTA>2.0.CO;2, 2003.

Scoccimarro, E., Fogli, P. G., Reed, K. A., Gualdi, S., Masina, S., and Navarra, A.: Tropical cyclone interaction with the ocean: The role of high-frequency (subdaily) coupled processes, J. Climate, 30, 145-162, https://doi.org/10.1175/JCLI-D-16-0292.1, 2017.

Simpson, R. H. and Saffir, H.: The hurricane disaster potential scale, Weatherwise, 27, 169-186, https://doi.org/10.1080/00431672.1974.9931702, 1974.

Small, R. J., Bacmeister, J., Bailey, D. A., Baker, A., Bishop, S., Bryan, F. O., Caron, J., Dennis, J., Gent, P. R., Hsu, H.-M., Jochum, M., Lawrence, D. M., Munoz Acevedo, E., diNezio, P., Scheitlin, T., Tomas, R., Tribbia, J., Tseng, Y., and Vertenstein, M.: A new synoptic scale resolving global climate simulation using the Community Earth System Model, J. Adv. Model. Earth Sy, 6, 1065-1094, https://doi.org/10.1002/2014MS000363, 2014

Strachan, J., Vidale, P. L., Hodges, K., Roberts, M., and Demory, M.-E.: Investigating global tropical cyclone activity with a hierarchy of AGCMs: The role of model resolution, J. Climate, 26, 133-152, https://doi.org/10.1175/JCLI-D-12-00012.1, 2013.

Ullrich, P. A. and Zarzycki, C. M.: TempestExtremes: a framework for scale-insensitive pointwise feature tracking on unstructured grids, Geosci. Model Dev., 10, 1069-1090, https://doi.org/10.5194/gmd-10-1069-2017, 2017.

Ullrich, P. A., Zarzycki, C. M., McClenny, E. E., Pinheiro, M. C., Stansfield, A. M., and Reed, K. A.: TempestExtremes v2.1: a community framework for feature detection, tracking, and analysis in large datasets, Geosci. Model Dev., 14, 5023-5048, https://doi.org/10.5194/gmd-14-5023-2021, 2021.

Vitart, F. and Robertson, A. W.: The sub-seasonal to seasonal prediction project (S2S) and the prediction of extreme events, Npj Clim. Atmos. Sci., 1, 3, https://doi.org/10.1038/s41612-0180013-0, 2018.

Vitart, F., Ardilouze, C., Bonet, A., Brookshaw, A., Chen, M., Codorean, C., Déqué, M., Ferranti, L., Fucile, E., and Fuentes, M.: The subseasonal to seasonal (S2S) prediction project database, B. Am. Meteorol. Soc., 98, 163-173, https://doi.org/10.1175/BAMS-D-16-0017.1, 2017.

Voldoire, A.: CNRM-CERFACS CNRM-CM6-1 model output prepared for CMIP6 HighResMIP highresSSTpresent, Earth System Grid Federation [data set], https://doi.org/10.22033/ESGF/CMIP6.4035, 2019a.
Voldoire, A.: CNRM-CERFACS CNRM-CM6-1-HR model output prepared for CMIP6 HighResMIP highresSSTpresent, Earth System Grid Federation [data set], https://doi.org/10.22033/ESGF/CMIP6.4036, 2019b.

Voldoire, A., Saint-Martin, D., Sénési, S., Decharme, B., Alias, A., Chevallier, M., Colin, J., Guérémy, J.-F., Michou, M., Moine, M.P., Nabat, P., Roehrig, R., Salas y Mélia, D., Séférian, R., Valcke, S., Beau, I., Belamari, S., Berthet, S., Cassou, C., Cattiaux, J., Deshayes, J., Douville, H., Franchisteguy, L., Ethé, C., Geoffroy, O., Lévy, C., Madec, G., Meurdesoif, Y., Msadek, R., Ribes, A., Sanchez-Gomez, E., and Terray, L.: Evaluation of CMIP6 deck experiments with CNRM-CM6-1, J. Adv. Model. Earth Sy., 11, 2177-2213, https://doi.org/10.1029/2019MS001683, 2019.

von Storch, J. S., Putrasahan, D., Lohmann, K., Gutjahr, O., Jungclaus, J., Bittner, M., Haak, H., Wieners, K. H., Giorgetta, M., Reick, C., Esch, M., Gayler, V., de Vrese, P., Raddatz, T., Mauritsen, T., Behrens, J., Brovkin, V., Claussen, M., Crueger, T., Fast, I., Fiedler, S., Hagemann, S., Hohenegger, C., Jahns, T., Kloster, S., Kinne, S., Lasslop, G., Kornblueh, L., Marotzke, J., Matei, D., Meraner, K., Mikolajewicz, U., Modali, K., Müller, W., Nabel, J., Notz, D., Peters-von Gehlen, K., Pincus, R., Pohlmann, H., Pongratz, J., Rast, S., Schmidt, H., Schnur, R., Schulzweida, U., Six, K., Stevens, B., Voigt, A., and Roeckner, E.: MPI-M MPIESM1.2-HR model output prepared for CMIP6 HighResMIP highresSST-present, Earth System Grid Federation [data set], https://doi.org/10.22033/ESGF/CMIP6.6584, 2017a.

von Storch, J. S., Putrasahan, D., Lohmann, K., Gutjahr, O., Jungclaus, J., Bittner, M., Haak, H., Wieners, K. H., Giorgetta, M., Reick, C., Esch, M., Gayler, V., de Vrese, P., Raddatz, T., Mauritsen, T., Behrens, J., Brovkin, V., Claussen, M., Crueger, T., Fast, I., Fiedler, S., Hagemann, S., Hohenegger, C., Jahns, T., Kloster, S., Kinne, S., Lasslop, G., Kornblueh, L., Marotzke, J., Matei, D., Meraner, K., Mikolajewicz, U., Modali, K., Müller, W., Nabel, J., Notz, D., Peters-von Gehlen, K., Pincus, R., Pohlmann, H., Pongratz, J., Rast, S., Schmidt, H., Schnur, R., Schulzweida, U., Six, K., Stevens, B., Voigt, A., and Roeckner, E.: MPI-M MPIESM1.2-XR model output prepared for CMIP6 HighResMIP highresSST-present, Earth System Grid Federation [data set], https://doi.org/10.22033/ESGF/CMIP6.10305, 2017b.

Voosen, P.: The weather master, Science, 356, 128-131, https://doi.org/10.1126/science.356.6334.128, 2017.

Walsh, K., Fiorino, M., Landsea, C., and McInnes, K.: Objectively determined resolution-dependent threshold criteria for the detection of tropical cyclones in climate models and reanalyses, J. Climate, 20, 2307-2314, https://doi.org/10.1175/JCLI4074.1, 2007.

Walsh, K., Lavender, S., Scoccimarro, E., and Murakami, H.: Resolution dependence of tropical cyclone formation in CMIP3 and finer resolution models, Clim. Dynam., 40, 585-599, https://doi.org/10.1007/s00382-012-1298-z, 2013.

Walsh, K. J., Camargo, S. J., Vecchi, G. A., Daloz, A. S., Elsner, J., Emanuel, K., Horn, M., Lim, Y.-K., Roberts, M., and Patricola, C.: Hurricanes and climate: the US CLIVAR working group on hurricanes, B. Am. Meteorol. Soc., 96, 997-1017, https://doi.org/10.1175/BAMS-D-13-00242.1, 2015.

Walsh, K. J., McBride, J. L., Klotzbach, P. J., Balachandran, S., Camargo, S. J., Holland, G., Knutson, T. R., Kossin, J. P., Lee, T. C., and Sobel, A.: Tropical cyclones and climate change, Wiley Interdiscip. Rev. Clim. Change, 7, 65-89, https://doi.org/10.1002/wcc.371, 2016. 
Williams, K. D., Copsey, D., Blockley, E. W., Bodas-Salcedo, A., Calvert, D., Comer, R., Davis, P., Graham, T., Hewitt, H. T., Hill, R., Hyder, P., Ineson, S., Johns, T. C., Keen, A. B., Lee, R. W., Megann, A., Milton, S. F., Rae, J. G. L., Roberts, M. J., Scaife, A. A., Schiemann, R., Storkey, D., Thorpe, L., Watterson, I. G., Walters, D. N., West, A., Wood, R. A., Woollings, T., and Xavier, P. K.: The Met Office global coupled model 3.0 and 3.1 (GC3. 0 and GC3. 1) configurations, J. Adv. Model. Earth Sy., 10, 357380, https://doi.org/10.1002/2017MS001115, 2018.

Wong, M. L. M. and Chan, J. C. L.: Tropical cyclone intensity in vertical wind shear, J. Atmos. Sci, 61, 1859-1876, https://doi.org/10.1175/15200469(2004)061<1859:TCIIVW>2.0.CO;2, 2004.

Wu, G. and Lau, N.-C.: A GCM simulation of the relationship between tropical-storm formation and ENSO, Mon. Weather Rev., 120, 958-977, https://doi.org/10.1175/15200493(1992)120<0958:AGSOTR>2.0.CO;2, 1992.

Wu, G., Liu, H., Zhao, Y., and Li, W.: A nine-layer atmospheric general circulation model and its performance, Adv. Atmos. Sci., 13, 1-18, https://doi.org/10.1007/BF02657024, 1996.

Xiang, B., Lin, S.-J., Zhao, M., Zhang, S., Vecchi, G., Li, T., Jiang, X., Harris, L., and Chen, J.-H.: Beyond weather timescale prediction for Hurricane Sandy and Super Typhoon Haiyan in a global climate model, Mon. Weather Rev., 143, 524-535, https://doi.org/10.1175/MWR-D-14-00227.1, 2015.

$\mathrm{Xu}, \mathrm{K} . \mathrm{-M}$. and Randall, D. A.: A semiempirical cloudiness parameterization for use in climate models, J. Atmos. Sci., 53, 3084-3102, https://doi.org/10.1175/15200469(1996)053<3084:ASCPFU>2.0.CO;2, 1996.

Ying, M., Zhang, W., Yu, H., Lu, X., Feng, J., Fan, Y., Zhu, Y., and Chen, D.: An overview of the China Meteorological Administration tropical cyclone database, J. Atmos. Ocean. Tech., 31, 287-301, https://doi.org/10.1175/JTECH-D-12-00119.1, 2014.

Yu, Y., Tang, S., Liu, H., Lin, P., and Li, X.: Development and evaluation of the dynamic framework of an ocean general circulation model with arbitrary orthogonal curvilinear coordinate, Chinese Journal of Atmospheric Sciences, 42, 877-889, https://doi.org/10.3878/j.issn.1006-9895.1805.17284, 2018.

Zarzycki, C. M. and Jablonowski, C.: Experimental tropical cyclone forecasts using a variable-resolution global model, Mon. Weather Rev., 143, 4012-4037, https://doi.org/10.1175/MWRD-15-0159.1, 2015.
Zhang, C.: Madden-Julian oscillation: Bridging weather and climate, B. Am. Meteorol. Soc., 94, 1849-1870, https://doi.org/10.1175/BAMS-D-12-00026.1, 2013.

Zhang, J. A., Rogers, R. F., and Tallapragada, V.: Impact of parameterized boundary layer structure on tropical cyclone rapid intensification forecasts in HWRF, Mon. Weather Rev., 145, 14131426, https://doi.org/10.1175/MWR-D-16-0129.1, 2017.

Zhang, W., Vecchi, G. A., Murakami, H., Delworth, T., Wittenberg, A. T., Rosati, A., Underwood, S., Anderson, W., Harris, L., and Gudgel, R.: Improved simulation of tropical cyclone responses to ENSO in the western North Pacific in the high-resolution GFDL HiFLOR coupled climate model, J. Climate, 29, 13911415, https://doi.org/10.1175/JCLI-D-15-0475.1, 2016.

Zhao, M., Held, I. M., Lin, S.-J., and Vecchi, G. A.: Simulations of global hurricane climatology, interannual variability, and response to global warming using a 50-km resolution GCM, J. Climate, 22, 6653-6678, https://doi.org/10.1175/2009JCLI3049.1, 2009.

Zhao, M., Held, I. M., and Lin, S. J.: Some counterintuitive dependencies of tropical cyclone frequency on parameters in a GCM, J. Atmos. Sci., 69, 2272-2283, https://doi.org/10.1175/JAS-D-110238.1, 2012.

Zhou, L., Bao, Q., Liu, Y., Wu, G., Wang, W. C., Wang, X., He, B., Yu, H., and Li, J.: Global energy and water balance: Characteristics from Finite-volume Atmospheric Model of the IAP/LASG (FAMIL1), J. Adv. Model. Earth Sy., 7, 1-20, https://doi.org/10.1002/2014MS000349, 2015.

Zhou, L., Lin, S. J., Chen, J. H., Harris, L. M., Chen, X., and Rees, S. L.: Toward Convective-Scale Prediction within the Next Generation Global Prediction System, B. Am. Meteorol. Soc., 100, 1225-1243, https://doi.org/10.1175/BAMS-D-17-0246.1, 2019.

Zhou, T., Turner, A. G., Kinter, J. L., Wang, B., Qian, Y., Chen, X., Wu, B., Wang, B., Liu, B., Zou, L., and He, B.: GMMIP (v1.0) contribution to CMIP6: Global Monsoons Model Inter-comparison Project, Geosci. Model Dev., 9, 3589-3604, https://doi.org/10.5194/gmd-9-3589-2016, 2016. 